\title{
A Hybrid Between TOA and Lévy Flight Trajectory for Solving Different Cluster Problems
}

\author{
Nagaraju Devarakonda, VIT-AP University, India \\ (iD) https://orcid.org/0000-0003-4864-8482 \\ Ravi Kumar Saidala, Koneru Lakshmaiah Education Foundation, Vaddeswaram, AP, India \\ (iD) https://orcid.org/0000-0002-3658-6651
}

Raviteja Kamarajugadda, LBR College of Engineering, India

\begin{abstract}
In data analysis applications for extraction of useful knowledge, clustering plays an important role. The major shortcoming of traditional clustering algorithms is exhibiting poor performance in solving complex data cluster problems. This research paper introduces a novel hybrid optimization techniquebased clustering approach. This paper is designed with two main objectives: designing efficient function optimization algorithm and developing advanced data clustering approach. In achieving the first objective, the standard TOA is first enhanced by hybridizing with Lévy flight trajectory and benchmarked on 23 functions. A new clustering approach is developed by conjoining k-means algorithm and Lévy flight TOA. The numerical complexity of the proposed novel clustering approach was tested on $10 \mathrm{UCI}$ clustering datasets and four web document cluster problems. Several simulation experiments were conducted and an analysis of the results was done. The obtained graphical and statistical analysis reveals that the proposed novel clustering approach yields better quality clusters.
\end{abstract}

\section{KEYWORDS}

Clustering Problems, Computational Intelligence, Nature-Inspired Metaheuristics, TOA Levy Flight Trajectory NP-Hard Problems, Web Document Cluster Problems

\section{INTRODUCTION}

Computational Intelligence (CI) is the fastest growing and promising area of study that have drawn more attention from the researchers over the years (Zadeh, L. A., et al., 2014). CI, also termed as Soft Computing in Lotfi Zadeh's terminology (Zadeh, L. A., 1996) is concerned with achieving of pattern recognition in data and structures in data (Wang, Y., 2017; Wang, Y., et al., 2016). CI is the only destination for many design and engineering researchers those who are working on modeling and analyzing complex systems (Pedrycz, W., Et al., 2014).CI embraces Nature-Inspired Metaheuristics (NIMs) like Bio-Inspired Computing (BIC), Swarm Intelligence (SI),Evolutionary Computations (EC), Metaphor-based Metaheuristics (MbM) and other Computational methodologies in solving NP-hard optimization problems (Bouarara, H. A., et al., 2015;Gheraibia, Y., et al., 2015;Kaynak, 
O., et al., 2012;Nouaouria, N., et al., 2014; Schor, D., \& Kinsner, W., 2011; Zadeh, L. A., 1973). Numerous successful applications of CI have been found in many design and engineering domains like data mining and knowledge discovery, pattern recognition, clinical decision making system, control system design, Market analysis and forecasting, etc. (Azar, A. T., \& Vaidyanathan, S. (Eds.), 2015).

Nature is the key source of rich models for solving computational problems. The algorithms which are designed by mimicking various phenomena existed in the nature for solving complex problems are called NIMs (Nanda, S. J., \& Panda, G., 2014). NIMs, a sub-field of CI, are popular, economical approaches for solving various problems, including tough optimization problems and NP-hard problems (Fister Jr, I., et al., 2013). There are several population based meta-heuristic optimization algorithms, for instance Particle Swarm Optimization (PSO) (Eberhart, R., \& Kennedy, J., 1995), Whale Optimization Algorithm (WOA) (Mirjalili, S., \& Lewis, A., 2016), Grey Wolf Optimization Algorithm (GWO) (Mirjalili, S., Et al., 2014), Tornadogenesis Optimization Algorithm (TOA) (Saidala, R. K., \& Devarakonda, N., 2017d), Salp Swarm Algorithm (SSA) (Mirjalili, S., Et al., 2017),New Class Topper Optimization Algorithm (Class TOA) (Das, P., Et al., 2018), etc. were developed and successfully applied to optimization problems. Population based NIMs have several unique features over other algorithms. These include collaborative learning, high exploration ability, decentralized control, and inspiration from the dynamic social behavior. Thus, many global optimization problems which can be observed frequently in many real-life applications like engineering, decision making, machine learning, statistics, optimal control, etc. (James, J. Q., \& Li, V. O., 2015;Li, X., Et al., 2014; Mirjalili, S., 2015; Saidala, R. K., \& Devarakonda, N., 2017b) are solved with low solution cost. Over the recent years NIMs were successfully dealing with various clustering problems. So, recently the research community has kept their special interests on developing new NIMs and applying them to various data cluster problems (Nanda, S. J., \& Panda, G.,2014;Saidala, R. K., \& Devarakonda, N., 2017a; Saidala, R. K., \& Devarakonda, N., 2018a).

Data analysis and data mining applications, clustering plays a vital role in extracting the useful hidden knowledge from the data (Witten, I. H., Et al., 2016; Xu, W., et al., 2017). In clustering task, the dataset is divided into homogeneous groups called clusters. These clusters must possess a higher degree of closeness ( similarity) among objects of each cluster and low degree of closeness (similarity) among objects of the other clusters (Jacques, J., \& Preda, C. 2014).Partition-based clustering, Hierarchy-based clustering, density-based clustering, and Grid-based approaches are the most wellknown clustering approaches (Bouyer, A., \& Hatamlou, A., 2018). The first approach, i.e. partitionbased clustering approach, the dataset is partitioned into homogeneous groups using some proximity function (Saidala, R. K., \& Devarakonda, N., 2018a; Xu, R., \& Wunsch, D., 2005).In case of hierarchic clustering approach the data is grouped over a variety of scales by generating a cluster tree or dendogram (Murtagh, F., 1983; Saidala, R. K., \& Devarakonda, N. R., 2017c). Density-based clustering approach, considers local density conditions instead of proximity between objects. (Kriegel, H. P., Et al., 2011 \&Saidala, R. K., \& Devarakonda, N. R., 2017c). The last approach, i.e. Grid-based approach, divides the data space into a finite number of cells to construct a grid like structure and form the homogeneous clusters of the grid cells (Nagpal, A., Et al., 2013).Among the other clustering algorithms, Partitional clustering approach is widely used in real-life applications due to exhibiting simplicity and linear-time complexity of data cluster problems. Traditional clustering algorithms are good at clustering simple datasets, but many of real-life application problems are complex in nature. That means traditional clustering techniques effectively solve the data cluster problems which are having less number of attributes and limited number of data instances. When there is an increase in both attribute count and number of instances the data analysis task become complex and traditional clustering algorithms fails to return good clusters (José-García, A., \& Gómez-Flores, W., 2016). In the Partitional data cluster approach, the collection of data objects is divided into set of homogeneous group(s) called cluster(s) such that inter-cluster dissimilarity is maximum or intra-cluster dissimilarity is minimum.This can be achieved by minimizing the quantization error which is an optimization problem. The quantization error $\left(J_{e}\right)$ is expressed as shown in Eq. (1). 
Table 1. Notations of Unimodal benchmark functions

\begin{tabular}{|l|l|c|}
\hline \multicolumn{1}{|c|}{ Function Description } & \multicolumn{1}{|c|}{ Range } & fmin \\
\hline$F_{1}(\operatorname{Dim}=30)=\sum_{i=1}^{n} x_{i}^{2}$ & {$[-100,100]$} & 0 \\
\hline$F_{2}(\operatorname{Dim}=30)=\sum_{\mathrm{i}=1}^{\mathrm{n}}\left|\mathrm{x}_{\mathrm{i}}\right|+\prod_{\mathrm{i}=1}^{\mathrm{n}}\left|\mathrm{x}_{\mathrm{i}}\right|$ & {$[10,10]$} & 0 \\
\hline$F_{3}(\operatorname{Dim}=30)=\sum_{\mathrm{i}=1}^{\mathrm{n}}\left(\sum_{\mathrm{j}-1}^{\mathrm{i}} \mathrm{x}_{\mathrm{j}}\right)^{2}$ & {$[-100,100]$} & 0 \\
\hline$F_{4}(\operatorname{Dim}=30)=\max _{\mathrm{i}}\left\{\left|\mathrm{x}_{\mathrm{i}}\right|, 1 \leq \mathrm{i} \leq \mathrm{n}\right\}$ & {$[-100,100]$} & 0 \\
\hline$F_{5}(\operatorname{Dim}=30)=\sum_{\mathrm{i}=1}^{\mathrm{n}-1}\left[100\left(\mathrm{x}_{\mathrm{i}+1}-\mathrm{x}_{\mathrm{i}}^{2}\right)^{2}+\left(\mathrm{x}_{\mathrm{i}}-1\right)^{2}\right]$ & {$[30,30]$} & \\
\hline$F_{6}(\operatorname{Dim}=30)=\sum_{\mathrm{i}=1}^{\mathrm{n}}\left(\left[\mathrm{x}_{\mathrm{i}}-0.5\right]\right)^{2}$ & {$[-100,100]$} & 0 \\
\hline$F_{7}(\operatorname{Dim}=30)=\sum_{\mathrm{i}=1}^{\mathrm{n}} \mathrm{ix}{ }_{\mathrm{i}}^{4}+$ random $[0,1)$ & {$[-1.28,1.28]$} & 0 \\
\hline
\end{tabular}

$$
J_{e}=\frac{\sum_{j=1}^{N_{c}}\left[\sum_{\forall Z_{p} \in C_{i j}} d\left(Z_{p}, m_{j}\right) /\left|C_{i j}\right|\right]}{N_{c}}
$$

Where $\left|C_{i j}\right|$ indicates the number of clusters $C_{i j}$ and $d$ represents the Euclidean distance function as described in Eq. (2).

$d\left(D_{T}, Z\right)=\sum_{i=1}^{n} \sum_{j=1}^{k}\left\|D_{T i j}-Z_{j}\right\|^{2}$

where $D_{T}$ represents the data point, $\mathrm{Z}$ specifies the cluster and $d\left(D_{T}, Z\right)$ represents the distance (Euclidean distance in this work) between $D_{T}$ and $Z$.

The ultimate objective of any good clustering technique is to discover the clusters of similar data objects by grouping the unlabeled input data where the similarity should be minimized between the objects of each cluster and maximize the same between objects of other clusters. This leads many researchers to consider the clustering problems as NP-hard problem which can be solved by an optimization algorithm (Das, P., Et al., 2018; Saidala, R. K., \& Devarakonda, N., 2017a). Many nature inspired Metaheuristics have been used successfully in solving various clustering problems. The whale 
Optimization based clustering approach was proposed by authors Saidala, R. K., \& Devarakonda, N., using multiple (Ring, Master-slave and hybrid) cooperative strategies (Saidala, R. K., \& Devarakonda, N., 2017c). Authors of (Saidala, R. K., \& Devarakonda, N., 2017d) proposed a new tornado formation based meta-heuristic algorithm termed as Tornadogenesis optimization Algorithm (TOA) to solve data cluster problems. The other versions of TOA (variants of TOA) were also proposed in solving data clustering problems (Saidala, R. K., \& Devarakonda, N., 2018b;Saidala, R. K., Et al., 2018c.A new optimal data clustering method was proposed for finding optimal clusters of data by introducing the Northern bald Ibis optimization Algorithm (NOA) (Saidala, R. K., \& Devarakonda, N., 2018d). Authors of (Saidala, R. K., Et al., 2018e; Saidala, R. K., Et al., 2018f) proposed various chaotic map based NOA for designing new clustering method and successfully applied to UCI and web document cluster datasets. This work presents the design of a new optimal clustering method using $k$-means clustering technique empowered by chaotic NOA (CNOA) for web document clustering. The key objective of the proposed CNOA based clustering method is to discover the best centroid location and increase the clustering accuracy.

Over the past few years, optimization algorithms have been applied successfully by the large proportion of researchers to solve numerous NP-hard problems. However, a major drawback of the majority of the existing algorithms is lacking of balancing between phases: exploration and exploitation (Mirjalili, S., Et al., 2017; Mirjalili, S., \& Lewis, A., 2016). The results with low solution cost are achieved to solve these problems in many cases by invoking hybrid strategies (Wang, G. G., Et al., 2014; Saremi, S., Et al., 2017). The theorem which became more popular, i.e., NFL (No Free Lunch) theorem (Wolpert, D. H., \& Macready, W. G., 1997) justifies that the number of new algorithms needed to solve complex problems with low solution cost. This paper presents the hybrid version of TOA in which Lévy flight trajectory is incorporated into the standard TOA to extend its function optimization capabilities and applying it to various cluster problems.

The rest of the research paper is framed as follows: The existing approach along with the pseudo code of the Hybrid Tornadogenesis Optimization algorithm is illustrated in Section 2. The proposed approach along with a neat flowchart and pseudo code is described in Section 3. The Section 4 summarizes the experimental analysis. The conclusions of the whole paper and outline of the future work is presented in Section 5.

\section{EXISTING APPROACH}

\section{Tornadogenesis Optimization Algorithm (TOA)}

\section{Brief Review of TOA}

Tornadogenesis optimization algorithm (TOA) is one of the recently developed optimization algorithm inspired by nature. TOA is a population based meta-heuristic algorithm which was developed to address benchmark function optimization and complex data cluster problems (Saidala, R. K., \& Devarakonda, N., 2017d). The formation of tornadoes, particularly in Oklahoma State of U.S., paved the path to develop a new algorithm named TOA.

The air around us is a mixture of molecules of warm and cool gases. The warm, humid and cool states of air molecules depend upon temperature, location, and time. The term "air mass" in meteorology is defined as large volume of air whose humidity, temperature and moisture properties are essentially homogeneous. The air in desert zones contains warm air masses wherein ocean zones contains cool or cold air masses. Oklahoma State is the centre place for having flow of warm, humid and cool air masses. The fact is that the unique geographical location of Oklahoma State permitting to have such air masses. Oklahoma State has the source of warm dry air masses from cities of Arizona and New Mexico, warm humid air masses from city of Gulf of Mexico, and cool air masses from the city of Canada. Meteorologists have done lot of study and research on "what makes the Oklahoma State leads the world's tornadoes?" and confirmed that the geographical location of Oklahoma State 
Table 2. Notations of Multimodal benchmark functions

\begin{tabular}{|c|c|c|}
\hline Function Description & Range & fmin \\
\hline$F_{8}(\operatorname{Dim}=30)=\sum_{\mathrm{i}=1}^{\mathrm{n}}-\mathrm{x}_{\mathrm{i}}^{2} \sin \left(\sqrt{\left|\mathrm{x}_{\mathrm{i}}\right|}\right)$ & {$[-500,500]$} & $-418.9829 * 5$ \\
\hline$F_{9}(\operatorname{Dim}=30)=\sum^{\mathrm{n}}\left[\mathrm{x}_{\mathrm{i}}^{2}-10 \cos \left(2 \pi \mathrm{x}_{\mathrm{i}}\right)+10\right]$ & {$[-5.12,5.12]$} & 0 \\
\hline$F_{10}(\operatorname{Dim}=30)=-20 \mathrm{e}^{\left(\ln _{\mathrm{i}=1}\right)}-\mathrm{e}^{\left(\mathrm{n}_{\mathrm{i}=1}\right)}+20+\mathrm{e}$ & {$[-32,32]$} & 0 \\
\hline$F_{11}(\operatorname{Dim}=30)=\frac{1}{4000} \sum_{i=1}^{\mathrm{n}} \mathrm{x}_{\mathrm{i}}^{2}-\prod_{\mathrm{i}=1}^{\mathrm{n}} \cos \left(\frac{\mathrm{x}_{\mathrm{i}}}{\sqrt{\mathrm{i}}}\right)+1$ & {$[-600,600]$} & 0 \\
\hline $\begin{array}{l}F_{12}(\operatorname{Dim}=30)=\frac{\pi}{\mathrm{n}}\left\{10 \sin \left(\pi \mathrm{y}_{1}\right)+\sum_{\mathrm{i}=1}^{\mathrm{n}-1}\left(\mathrm{y}_{\mathrm{i}}-1\right)^{2}\left[1+10 \sin \pi \mathrm{y}_{\mathrm{i}+1}^{2}\right]+\right. \\
\left.\left(\mathrm{y}_{\mathrm{n}}-1\right)^{2}\right\}+\sum_{\mathrm{i}-1}^{\mathrm{n}} \mathrm{u}\left(\mathrm{x}_{\mathrm{i}}, 10,100,4\right)\end{array}$ & {$[-50,50]$} & 0 \\
\hline $\mathrm{y}_{\mathrm{i}}=1+\frac{\mathrm{x}_{\mathrm{i}}+1}{4} \mathrm{u}\left(\mathrm{x}_{\mathrm{i}}, \mathrm{a}, \mathrm{k}, \mathrm{m}\right)=\left\{\begin{array}{lr}k\left(\mathrm{x}_{\mathrm{i}}-\mathrm{a}\right)^{\mathrm{m}} & \mathrm{x}_{\mathrm{i}}>a \\
0 & -a<\mathrm{x}_{\mathrm{i}}<a \\
k\left(-\mathrm{x}_{\mathrm{i}}-\mathrm{a}\right)^{\mathrm{m}} & \mathrm{x}_{\mathrm{i}}<-a\end{array}\right.$ & & \\
\hline $\begin{array}{l}F_{13}(\operatorname{Dim}=30)=0.1\left\{\sin \left(3 \pi \mathrm{x}_{1}\right)^{2}+\sum_{\mathrm{i}=1}^{\mathrm{n}}\left(\mathrm{x}_{\mathrm{i}}-1\right)^{2}\left[1+\sin \left(3 \pi \mathrm{x}_{\mathrm{i}}+1\right)^{2}\right]+\right. \\
\left.\left.\left(\mathrm{x}_{\mathrm{n}}-1\right)^{2}\left[1+\sin 2 \grave{\mathrm{A}} \mathrm{x}_{\mathrm{n}}\right)^{2}\right]+\sum_{\mathrm{i}-1}^{\mathrm{n}} \mathrm{u}\left(\mathrm{x}_{\mathrm{i}}, 5,100,4\right)\right\}\end{array}$ & {$[-50,50]$} & 0 \\
\hline$F_{14}(\operatorname{Dim}=2)=\left(\frac{1}{500} \sum_{\mathrm{j}=1}^{25} \frac{1}{\mathrm{j}+\sum^{2}\left(\mathrm{x}_{\mathrm{i}}-\mathrm{a}_{\mathrm{ij}}\right)^{6}}\right)^{-1}$ & {$[-65,65]$} & 1 \\
\hline$F_{15}(\operatorname{Dim}=4)=\sum_{\mathrm{i}=1}^{11}\left[\mathrm{a}_{\mathrm{i}}-\frac{\mathrm{x}_{1}\left(\mathrm{~b}_{\mathrm{i}}^{2}+\mathrm{b}_{\mathrm{i}} \mathrm{x}_{2}\right)}{\mathrm{b}_{\mathrm{i}}^{2}+\mathrm{b}_{\mathrm{i}} \mathrm{x}_{3}+\mathrm{x}_{4}}\right]^{2}$ & {$[-5,5]$} & 0.0003 \\
\hline$F_{16}(\operatorname{Dim}=2)=4 \mathrm{x}_{1}^{2}-2.1 \mathrm{x}_{1}^{4}+\frac{1}{3} \mathrm{x}_{1}^{6}+\mathrm{x}_{1} \mathrm{x}_{2}-4 \mathrm{x}_{2}^{2}+4 \mathrm{x}_{2}^{4}$ & {$[-5,5]$} & 1.0316 \\
\hline$F_{17}(\operatorname{Dim}=2)=\left(\mathrm{x}_{2}-\frac{5.1}{4 \pi^{2}} \mathrm{x}_{1}^{2}+\frac{5}{\pi} \mathrm{x}_{1}-6\right)^{2}+10\left(1-\frac{1}{8 \pi}\right) \cos \mathrm{x}_{1}+10$ & {$[-5,5]$} & 0.398 \\
\hline
\end{tabular}




\begin{tabular}{|c|c|c|}
\hline Function Description & Range & fmin \\
\hline $\begin{array}{l}F_{18}(\operatorname{Dim}=2)=\left[1+\left(\mathrm{x}_{1}+\mathrm{x}_{2}+1\right)^{2}\left(\begin{array}{c}19-14 \mathrm{x}_{1}+ \\
3 \mathrm{x}_{1}^{2}-14 \mathrm{x}_{2}+6 \mathrm{x}_{1} \mathrm{x}_{2}\end{array}\right)+3 \mathrm{x}_{2}^{2}\right] * \\
{\left[30+\left(2 \mathrm{x}_{1}-3 \mathrm{x}_{2}\right)^{2} *\left(18-32 \mathrm{x}_{1}+12 \mathrm{x}_{1}^{2}+48 \mathrm{x}_{2}-36 \mathrm{x}_{1} \mathrm{x}_{2}+27 \mathrm{x}_{2}^{2}\right)\right]}\end{array}$ & {$[-5,5]$} & 3 \\
\hline$F_{19}(\operatorname{Dim}=3)=-\sum_{\mathrm{i}=1}^{4} \mathrm{c}_{\mathrm{i}} \mathrm{e}^{\left(-\sum_{\mathrm{j}=1}^{3} \mathrm{a}_{\mathrm{ij}}\left(\mathrm{x}_{\mathrm{j}}-\mathrm{p}_{\mathrm{ij}}\right)^{2}\right)}$ & {$[1,3]$} & -3.86 \\
\hline$F_{20}(D i m=6)=-\sum_{\mathrm{i}=1}^{4} c_{\mathrm{i}} \mathrm{e}^{\left(-\sum_{\mathrm{j}=1}^{\left.\mathrm{a}_{\mathrm{ij}}\left(\mathrm{x}_{\mathrm{j}}-\mathrm{p}_{\mathrm{ij}}\right)^{2}\right)}\right.}$ & {$[0,1]$} & -3.32 \\
\hline$F_{21}(\operatorname{Dim}=4)=-\sum_{\mathrm{i}=1}^{5}\left[\left(\mathrm{x}-\mathrm{a}_{\mathrm{i}}\right)\left(\mathrm{x}-\mathrm{a}_{\mathrm{i}}\right)^{\mathrm{T}}+\mathrm{c}_{\mathrm{i}}\right]^{-1}$ & {$[0,10]$} & -10.1532 \\
\hline$F_{22}(\operatorname{Dim}=4)=-\sum_{\mathrm{i}=1}^{7}\left[\left(\mathrm{X}-\mathrm{a}_{\mathrm{i}}\right)\left(\mathrm{X}-\mathrm{a}_{\mathrm{i}}\right)^{\mathrm{T}}+\mathrm{c}_{\mathrm{i}}\right]^{-1}$ & {$[0,10]$} & -10.4028 \\
\hline$F_{23}(\operatorname{Dim}=4)=-\sum_{\mathrm{i}=1}^{10}\left[\left(\mathrm{X}-\mathrm{a}_{\mathrm{i}}\right)\left(\mathrm{X}-\mathrm{a}_{\mathrm{i}}\right)^{\mathrm{T}}+\mathrm{c}_{\mathrm{i}}\right]^{-1}$ & {$[0,10]$} & -10.5363 \\
\hline
\end{tabular}

and this state is surrounded by various sources of cool and warm air masses. Typically the formation of tornadoes supervention with the expeditiously revolving columns of mixed cold and warm air masses that configure inside the storms and then extends to the surface of the earth via funnel of the cloud. The formation of tornadoes by collision of cool and warm air masses inspired the authors towards the development of new optimization algorithm.

\section{Formulation of TOA}

The mathematical modelling of the TOA is designed in three phases as follows:

\section{Initialization Phase}

This phase details the initialization of required parameters and delineation of the problem. The required parameters that are to be initialized are population of air masses (AM_Pop), Count of design parameters (Dim), Cost function: fcost, Maximum number of iterations for terminations (Max_Iter), lower and upper boundaries of the design parameter: $\left[l b_{1}, l b_{2}, \ldots, l b_{n}\right]$ to $\left[u b_{1}, u b_{2}, \ldots, u b_{n}\right]$. These boundaries should satisfy the following condition: $l b_{i} \leq A M_{i} \geq u b_{i}$.

\section{Tornado Formation Phase}

The tornado formation at Oklahoma State is happened to be occurring in two different ways. They are: (I) the direction of cool and warm air masses is in the same direction and (II) the direction of cool 
Table 3. Pseudo code of TOA-BBBC

\section{INPUT: Initial air mass population $A M_{i} t, p$, Maximum number of iterations (Max_Iter),}

OUTPUT: $A M^{*}$ Optimal solution

1. Initialize population $A M_{(i=1,2, \ldots, \mathrm{n})}$

2. Compute fitness $f_{a m}$ for individual candidate

3. discover position of the best candidate solution $A M^{*}$

4. $\quad$ while $(\mathrm{t}<$ Max_Iter $)$

5. for1 each $A M_{i}$

6. if1 $(\mathrm{p}<0.5)$

7. Update the current candidate positionwith Eq.(4)

8. $\quad$ elseif1 $\left(p^{3} 0.5\right)$

9. Update the current candidate position with Eq. (5)

10. end if1

11. end for 1

12. createnew population $A M_{n}^{j}, j=1,2,3, \ldots \ldots k$ using Eq. (9)

13. amend if any search candidate goes beyond the search space

14. for2 $A M_{n}^{j}, \quad j=1,2,3, \ldots \ldots k$

15. determine fitness fam $\ldots$ new of $A M_{n}^{j}$

16. New best solution $A M_{n e w}^{*}$

\begin{tabular}{|r|l|}
\hline 17. & if2 $f a m \_n e w>f_{a m}$ \\
\hline 18. & $A M^{*}=A M_{n e w}^{*}$ and $f_{a m}=f a m \_n e w$ \\
\hline 19. & end if2 \\
\hline 20. & end for2 \\
\hline 21. & $t=t+1$ \\
\hline 22. & end while \\
\hline 23. & return $A M^{*}$ \\
\hline
\end{tabular}


and warm air masses is in the opposite direction. In TOA formulation, it is assumed that the chance of happening of warm and cool air mass collision when they are in the same direction and the opposite direction is $50 \%$ and $50 \%$ respectively. The formation of tornadoes is expressed mathematically as stated as in Eq. (4) and (5).

If $p \geq 0.5$

$\overrightarrow{A M}_{(t+1)} \leftarrow A F \cdot b l \cdot \cos (\cot l) \cdot 2 \pi-\overrightarrow{A M}_{(t)}^{*}$

If $p \geq 0.5$

$\overrightarrow{A M}_{(t+1)} \leftarrow E \cdot \cos (\cot l) \cdot \pi / 2$

Where $p=<0.5$

$l=(-1)+2 . \times \operatorname{rand}()$

$E \leftarrow A F \cdot b l \cdot \cos (\cot l) \cdot 2 \pi-\overrightarrow{A M}_{(t)}^{*}$

$A F$ is the additional force required to form a tunnel structure in improving phase. $A F$ is defined as follows:

$$
\overrightarrow{A F} \leftarrow\left|\overrightarrow{A M}_{(t)}^{*}-\overrightarrow{A M}_{(t)}\right|
$$

where $\overrightarrow{A M}_{(t)}^{*}$ denotes the position vector of the candidate having the best fitness and $\overrightarrow{A M}_{(t)}$ is the position vector.

\section{Termination Phase}

Both Improving and tornado formation phases are repeated until the iteration count reach to the maximum number of iterations. Only after the successful execution of the TOA algorithm by meeting the termination criteria, the optimal position of search candidates in terms of cost function value will be returned.

\section{BB-BC Algorithm}

The BB-BC, a novel heuristic approach, was designed by taking inspiration from the well-known evolutionary theory; namely, big bang (BB) and big crunch (BC) theories (Erol, O. K., \& Eksin, I., 2006). The mathematical formulation of big bang and big crunch gives rise to develop a new optimization algorithm. In the mathematical formulation of $\mathrm{BB}-\mathrm{BC}$, the particles are treated as solution candidates. According to BB-BC algorithm, all of randomly distributed candidate solutions 
will be dragged into the center point through the center of the candidate in the BC phase. This can be formulated in an equation form as shown in Eq. (8).

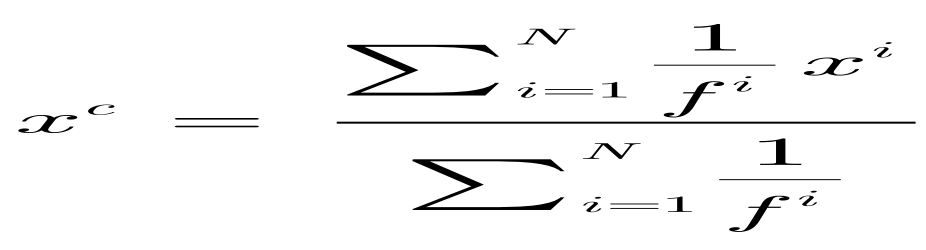

where $N$ depicts the total number of candidate solutions $x^{i}$ denotes the position of the $i^{\text {th }}$ candidate solution. $f^{i}$ represents the fitness values of the $i^{\text {th }}$ candidate solution. The BB phase new candidate solutions will be generated using the formulae as shown in Eq. (9).

$$
x_{n e w}^{i}=x^{c}+\frac{l r}{k} \quad i=1,2, \ldots, N
$$

Where $k$ represents the iteration number, $r$ represents the random number from the standard normal distribution in the range $[0,1]$. In Eq. (9), the parameter $l$ limits search space size.

\section{TOA -BBBC (TOA HYBRIDIZED WITH BB-BC)}

The local optima and the premature convergence are the two issues usually observed in many Metaheuristics. To overcome these issues several performance improving methods such as invoking chaotic maps, embedding other algorithms into the standard algorithm etc. are used by many researchers. The hybridization TOA with BB-BC is such type. The standard TOA was enhanced by hybridized it with BB-BC algorithm. The pseudo code of TOA -BBBC is presented in Table 4.

\section{PROPOSED APPROACH}

\section{Brief Review of Lévy Flight Algorithm}

Over hundred years ago the random way of movement was given with a name called Brownian motion. As time moved upon based on the real time instances a French mathematician named Paul Levy in the year 1937 has come to another kind of random movement with some mathematical pattern of movement as Levy flight or Levy walk. It is distinguished with tiny movements connected with infrequent long movements. Most of the steps in this pattern are within a small area and occasionally long moves takes place. Levy like patterns usually found in birds, bees, land mammals, sharks, spiders and even bacteria as well. Common examples of levy flight are like Animals when hunting make random clustering movements to find food in small spaces. When they felt they probably got exhausted their possibilities in an area, they bolt in one random direction for a while and clusters again for food. Affirmation regarding levy flight is seen as random movement of people in university campuses, urban environment. In day to day life people stay in certain part of an area and move towards another direction for work which means they move in small areas for some time and jumps long for work shows a levy pattern. Considering the behaviour of sharks looking

Paul Levy made a general statement beyond the Brownian motion examining other probability distributions for which a single jump or $N$ jumps contribute to a common mathematical form. Based on the power law $1 / x 1+\gamma$ for large $x$ values where $0\langle\gamma\rangle 2$ the levy distributions tend to decreases. 


\section{Table 4. Pseudo code of LTOA}

\section{INPUT: Initial air mass population $A M_{i} t, p$, Maximum number of iterations,}

OUTPUT: $A M^{*}$ Optimal solution

\begin{tabular}{|c|c|}
\hline 1. & Initialize population $A M_{(i=1,2, \ldots, \mathrm{n})}$ \\
\hline 2. & Compute fitness $f_{a m}$ for individual candidate \\
\hline 3. & discover position of the best candidate solution $A M^{*}$ \\
\hline 4. & Update $p$ \\
\hline 5. & For1 each candidate \\
\hline 6. & if1 $\mathrm{p}<0.5$ \\
\hline 7. & Update the current candidate position with Eq. (4) \\
\hline 8. & else if $1 p^{3} 0.5$ \\
\hline 9. & Update the current candidate position with Eq. (5) \\
\hline 10 & amend if any search candidate goes beyond the search space \\
\hline 11. & end if1 \\
\hline 12. & end for1 \\
\hline 13 & For2 each candidate \\
\hline 14 & Update the current candidate positionwith the Lévy flight Eq. (12) \\
\hline 15 & end for2 \\
\hline 16 & amend if any search candidate goes beyond the search space \\
\hline 17. & compute the fitness $\boldsymbol{f}_{\boldsymbol{a}}$ of each candidate \\
\hline 18. & Update $A M^{*}$ if found better solution \\
\hline 19 & repeatuntil Max_Iter \\
\hline 20. & return $A M^{*}$ \\
\hline
\end{tabular}

When $\gamma=2$, the Brownian motion trend to be the utmost case of Levy motion (Jensi, R., \& Jiji, G. W., 2016; Kamaruzaman, A. F., et al., 2013). The mathematical formulation of a simple Lévy flight distribution in terms of Fourier transform is presented as shown in Eq. (10) and (11) respectively.

$$
L(s, \gamma, \mu)= \begin{cases}\sqrt{\frac{\gamma}{2 \pi}} \exp ^{\left[-\frac{\gamma}{2(s-\mu)}\right]} \frac{1}{(s-\mu)^{\frac{3}{2}}}, \text { if } 0<\mu<s \infty & \\ 0, & \text { if } s \leq 0\end{cases}
$$

where $\gamma$ represents a scale parameter and $\gamma>0$ 
$\mu$ denotes the location or shift parameter.

$F(k)=\exp ^{\left[-\alpha|k|^{\beta}\right]}, 0<\beta \leq 2$

where $\alpha$ denotes skewness or scale factor parameter, $\alpha$ lies within $[-1,1]$ interval. The typical Lévy flight trajectory plot is presented in Figure (1).

\section{TOA-Lévy flight (A hybrid between TOA and Lévy flight)}

The standard TOA works-well for optimization problems. But for high dimensional and also for multimodal function problems it returns poor results. The existing approach is discussed in Section II,

BBBC was used to a achieve enhancement in phases exploration and exploitation, and avoids premature convergence. This paper proposes a hybrid between standard TOA and Lévy flight trajectory termed in this work as Lévy flight Tornadogenesis Optimization Algorithm (LTOA) for achieving better optimization results for higher dimensional function problems. It is observed by many researchers that the Lévy flight algorithm maximizes the diversification of search candidates. This enables the accomplishment of local minima avoidance in the algorithm. The utilization of Lévy flight algorithm in enhancement of standard optimization algorithm was done by many researchers and confirmed the improved optimization performance. Therefore, in this work Lévy flight is used for enhancing the performance of TOA for high dimensional problems. The position update of candidate positions after the position updating (using Eq. (4) or (5) based on $p$ value) in the standard TOA algorithm can be mathematically formulated as shown in Eq. (12).

$$
\overrightarrow{A M}_{(t+1)} \leftarrow \overrightarrow{A M}_{(t)}+\mu \sin [\text { rand }-1 / 2] \oplus \text { Lévy }
$$

Where the product $\oplus$ denotes entrywise multiplication. $\overrightarrow{A M}_{(t)}$ indicates the $i^{\text {th }}$ air mass or the position vector $\overrightarrow{A M}$ at $t$ (where t denotes current iteration). The parameter $\mu$ denotes random number that is consistent with a uniform distribution. rand denotes a random number in the range of $[0,1]$. The Lévy distribution is presented in Eq. (13).

$$
\text { Lévy } \sim=t^{-\lambda}, 1<\lambda \leq 3
$$

For generating random step sizes, in this work Mantegna algorithm is used for symmetric Lévy stable distribution. According to Mantega's algorithm (Yang, 2010b), the expression for step length $s$ as shown in Eq. (14).

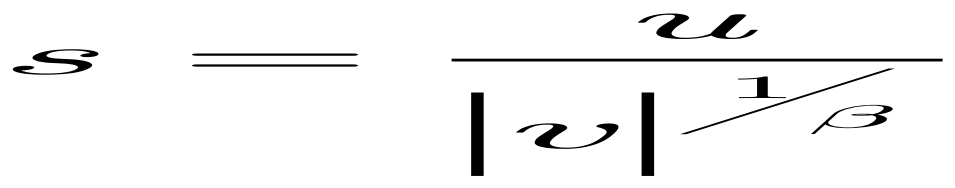


Table 5. Statistical analysis of acquired solution cost for F1 to F23

\begin{tabular}{|c|c|c|c|c|c|c|c|c|c|c|}
\hline Alg. & Average & Median & Std. Dev & Best & Worst & Average & Median & Std. Dev & Best & Worst \\
\hline & \multicolumn{5}{|c|}{$F 1$} & \multicolumn{5}{|c|}{$F 2$} \\
\hline WOA & 976.093 & $1.5 \mathrm{e}-29$ & $6.1 e+3$ & $1.7 \mathrm{e}-81$ & $6.242 \mathrm{e}+4$ & $2.921 \mathrm{e}+7$ & $1.703 \mathrm{e}-18$ & $4.613 \mathrm{e}+8$ & $3.423 \mathrm{e}-52$ & $7.302 \mathrm{e}+9$ \\
\hline TOA & 143.231 & $1.8 \mathrm{e}-154$ & $2.63 e+3$ & $2 e-316$ & $5.802 \mathrm{e}+4$ & $3.945 \mathrm{e}+7$ & $4.454 \mathrm{e}-82$ & $8.820 \mathrm{e}+8$ & $\begin{array}{l}1.179 \mathrm{e}- \\
165\end{array}$ & $1.97 \mathrm{e}+10$ \\
\hline HTOA & 142.380 & $7.6 e-164$ & $2.18 \mathrm{e}+3$ & 0 & $6.622 \mathrm{e}+4$ & $1.410 \mathrm{e}+6$ & $3.612 \mathrm{e}-81$ & $7.153 \mathrm{e}+7$ & $\begin{array}{l}1.309 \mathrm{e}- \\
169\end{array}$ & $2.428 \mathrm{e}+9$ \\
\hline \multirow[t]{2}{*}{ LTOA } & 70.0512 & $1.3 \mathrm{e}-183$ & $2.07 e+3$ & 0 & $5.272 \mathrm{e}+4$ & $1.625 \mathrm{e}+6$ & $2.133 e-85$ & $6.001 \mathrm{e}+7$ & $\begin{array}{l}1.539 \mathrm{e}- \\
143\end{array}$ & $1.165 \mathrm{e}+9$ \\
\hline & \multicolumn{5}{|c|}{ F3 } & \multicolumn{5}{|c|}{$F 4$} \\
\hline WOA & $5.81 \mathrm{e}+4$ & $5.3 e+4$ & $3.44 \mathrm{e}+4$ & $1.7 e+4$ & $1.269 \mathrm{e}+5$ & 1.4157 & $2.208 \mathrm{e}-35$ & 5.2690 & $6.357 \mathrm{e}-38$ & 90.7160 \\
\hline TOA & 233.564 & $2.8 \mathrm{e}-132$ & $3.89 e+3$ & 0 & $8.310 \mathrm{e}+4$ & 0.3498 & $4.467 e-67$ & 4.3485 & $2.531 \mathrm{e}-135$ & 82.9751 \\
\hline HTOA & 224.601 & $2.5 e-34$ & $3.96 e+3$ & 0 & $8.145 \mathrm{e}+4$ & 0.2498 & $4.154 \mathrm{e}-71$ & 4.1126 & 0 & 82.4402 \\
\hline \multirow[t]{2}{*}{ LTOA } & 196.811 & $2.6 e-64$ & $2.86 e+3$ & 0 & $1.304 \mathrm{e}+3$ & 0.2412 & $3.342 \mathrm{e}-83$ & 4.0054 & 0 & 81.9015 \\
\hline & \multicolumn{5}{|c|}{$F 5$} & \multicolumn{5}{|c|}{ F6 } \\
\hline WOA & $2.61 \mathrm{e}+6$ & 27.9527 & $1.94 \mathrm{e}+7$ & 27.952 & $2.54 \mathrm{e}+8$ & 629.8011 & 0.3204 & $4.798 \mathrm{e}+3$ & 0.3204 & $5.528 \mathrm{e}+4$ \\
\hline TOA & $6.69 e+5$ & 26.9503 & $3.20 \mathrm{e}+6$ & 28.940 & $2.12 \mathrm{e}+8$ & 107.5311 & 0.4654 & $2.391 \mathrm{e}+3$ & 0.0187 & $6.289 e+4$ \\
\hline HTOA & $5.15 e+5$ & 26.0428 & $3.07 e+6$ & 28.166 & $2.22 \mathrm{e}+8$ & 131.0568 & 0.3454 & $3.465 \mathrm{e}+3$ & 0.2715 & $5.66 \mathrm{e}+25$ \\
\hline LTOA & $3.24 \mathrm{e}+3$ & 26.4203 & $3.15 \mathrm{e}+6$ & 27.840 & $2.41 \mathrm{e}+8$ & 106.6108 & 0.3145 & $2.382 \mathrm{e}+3$ & 0.2604 & $6.205 \mathrm{e}+4$ \\
\hline \multicolumn{6}{|c|}{ F7 } & \multicolumn{5}{|c|}{$F 8$} \\
\hline WOA & 1.3233 & 0.0057 & 11.144 & 0.0052 & 139.6725 & $-1.15 e+4$ & $-1.233 e+4$ & $1.749 \mathrm{e}+3$ & $-1.235 \mathrm{e}+4$ & $-2.45 e+3$ \\
\hline TOA & 0.2595 & $4.46 \mathrm{e}-4$ & 5.4104 & $9.01 \mathrm{e}-5$ & 120.7298 & $-3.17 e+3$ & $-2.860 e+3$ & 635.6914 & $-4.374 e+3$ & $-1.79 e+3$ \\
\hline HTOA & 0.1862 & $2.65 \mathrm{e}-4$ & 4.1831 & $4.67 e-5$ & 120.5418 & $-2.65 e+4$ & $-1.655 e+4$ & $1.254 \mathrm{e}+3$ & $-1.252 \mathrm{e}+4$ & $-3.11 e+3$ \\
\hline \multirow[t]{2}{*}{ LTOA } & 0.1604 & $1.98 \mathrm{e}+4$ & 4.6574 & 0.0099 & 140.5608 & $-3.35 e+4$ & $-1.163 e+4$ & $1.375 \mathrm{e}+3$ & $-1.206 e+4$ & $-1.83 e+3$ \\
\hline & \multicolumn{5}{|c|}{ F9 } & \multicolumn{5}{|c|}{$F 10$} \\
\hline WOA & 27.121 & 0 & 76.7544 & 0 & 450.6246 & 0.4300 & $6.217 \mathrm{e}-15$ & 2.5248 & $4.44 \mathrm{e}-15$ & 20.4593 \\
\hline TOA & 9.1750 & 0 & 48.0624 & 0 & 435.2462 & 0.1464 & $8.882 \mathrm{e}-16$ & 1.4175 & $8.882 \mathrm{e}-16$ & 20.2126 \\
\hline HTOA & 9.0452 & 0 & 24.6906 & 0 & 425.3651 & 0.1352 & $8.882 \mathrm{e}-16$ & 0.9811 & $8.882 \mathrm{e}-16$ & 20.2281 \\
\hline \multirow[t]{2}{*}{ LTOA } & 8.1609 & 0 & 46.6115 & 0 & 422.8401 & 0.1286 & $7.417 \mathrm{e}-14$ & 1.5048 & $4.206 \mathrm{e}-13$ & 20.0461 \\
\hline & \multicolumn{5}{|c|}{$F 11$} & \multicolumn{5}{|c|}{$F 12$} \\
\hline WOA & 6.8496 & 0 & 51.1150 & 0 & 573.1051 & $6.54 e+6$ & 0.0472 & $5.601 \mathrm{e}+7$ & 0.0472 & $7.440 \mathrm{e}+8$ \\
\hline TOA & 1.9288 & 0 & 27.1083 & 0 & 589.0046 & $1.02 \mathrm{e}+6$ & 0.0023 & $2.238 \mathrm{e}+7$ & 0.7495 & $5.003 \mathrm{e}+8$ \\
\hline HTOA & 1.5153 & 0 & 27.0531 & 0 & 581.8904 & $1.05 \mathrm{e}+6$ & 0.0151 & $2.168 \mathrm{e}+7$ & 0.0451 & $4.005 \mathrm{e}+8$ \\
\hline \multirow[t]{2}{*}{ LTOA } & 1.3804 & 0 & 32.6618 & 0 & 571.9568 & $1.26 \mathrm{e}+6$ & 0.0876 & $2.322 \mathrm{e}+7$ & 0.0307 & $4.739 \mathrm{e}+8$ \\
\hline & \multicolumn{5}{|c|}{$F 13$} & \multicolumn{5}{|c|}{$F 14$} \\
\hline WOA & $9.61 e+6$ & 0.2720 & $8.26 e+7$ & 0.2720 & $9.539 \mathrm{e}+8$ & 3.4340 & 2.9821 & 2.6263 & 2.9821 & 43.0259 \\
\hline TOA & $2.70 e+6$ & 2.9942 & $4.67 e+7$ & 2.9927 & $1.044 \mathrm{e}+9$ & 0.0051 & 0.0046 & 0.0271 & 0.0014 & 0.5577 \\
\hline HTOA & $2.05 e+6$ & 0.3451 & $4.83 e+7$ & 0.8245 & $2.551 \mathrm{e}+9$ & 0.0144 & 0.1445 & 0.2557 & 0.0457 & 43.5165 \\
\hline LTOA & $2.30 \mathrm{e}+6$ & 0.2891 & $4.37 \mathrm{e}+7$ & 0.5051 & $1.355 \mathrm{e}+9$ & 4.0912 & 2.0681 & 0.6913 & 0.9241 & 44.6605 \\
\hline
\end{tabular}


Table 5. Continued

\begin{tabular}{|c|c|c|c|c|c|c|c|c|c|c|}
\hline Alg. & Average & Median & Std. Dev & Best & Worst & Average & Median & Std. Dev & Best & Worst \\
\hline & \multicolumn{5}{|c|}{$F 15$} & \multicolumn{5}{|c|}{$F 16$} \\
\hline WOA & 0.0015 & $3.3 e-4$ & 0.0205 & $3.29 \mathrm{e}-4$ & 0.4502 & -1.0305 & -1.0316 & 0.0089 & -1.0316 & -0.8963 \\
\hline TOA & 0.0051 & 0.0046 & 0.0271 & 0.0014 & 0.5577 & -1.0298 & -1.0316 & 0.0393 & -1.0316 & -0.1519 \\
\hline HTOA & 0.0094 & 0.1574 & 0.0571 & 0.0564 & 0.9004 & -1.4581 & -1.0642 & 0.0716 & -0.0572 & 0.4786 \\
\hline \multirow[t]{2}{*}{ LTOA } & 0.0065 & 0.1681 & 0.0589 & 0.0653 & 0.1663 & -1.0751 & -1.6804 & 0.8163 & -0.4056 & 0.9348 \\
\hline & \multicolumn{5}{|c|}{ F17 } & \multicolumn{5}{|c|}{ F18 } \\
\hline WOA & 0.4256 & 0.3982 & 0.1260 & 0.3979 & 1.2673 & 3.5112 & 3.0000 & 3.5737 & 3.0000 & 34.9664 \\
\hline TOA & 0.9949 & 0.9973 & 0.0233 & 0.7631 & 0.9973 & 12.4007 & 17.3028 & 6.4413 & 3.0171 & 17.3028 \\
\hline HTOA & 0.2454 & 0.2564 & 0.5155 & 0.3281 & 0.9541 & 8.5056 & 3.5497 & 0.5548 & 2.9454 & 19.5065 \\
\hline \multirow[t]{2}{*}{ LTOA } & 0.5938 & 0.6441 & 0.0844 & 0.2711 & 0.7662 & 4.5905 & 2.6204 & 3.4541 & 3.4651 & 19.0861 \\
\hline & \multicolumn{5}{|c|}{$F 19$} & \multicolumn{5}{|c|}{$F 20$} \\
\hline WOA & -3.8218 & -3.8560 & 0.0616 & -3.8565 & -3.4609 & -2.9480 & -2.9899 & 0.0695 & -2.9900 & -2.3866 \\
\hline TOA & -3.8589 & -3.8589 & $2.99 \mathrm{e}-14$ & -3.8589 & -3.8589 & -1.4698 & -1.4698 & $1.756 \mathrm{e}-14$ & -1.4698 & -1.4698 \\
\hline HTOA & -3.7545 & -3.8501 & 0.2451 & -3.5454 & -3.4521 & -3.5410 & -3.1541 & $0.566 \mathrm{e}-14$ & -2.5454 & -0.5408 \\
\hline \multirow[t]{2}{*}{ LTOA } & -3.9371 & -3.5693 & 0.5414 & -3.4305 & -3.3565 & -3.3187 & -3.0815 & $0.406 e-15$ & 0.0615 & -1.6504 \\
\hline & \multicolumn{5}{|c|}{$F 21$} & \multicolumn{5}{|c|}{$F 22$} \\
\hline WOA & -4.9423 & -5.0547 & 0.4996 & -5.0547 & -0.5249 & -3.6383 & -3.7213 & 0.3054 & -3.7213 & -0.5457 \\
\hline TOA & -0.9142 & -0.9142 & $1.04 \mathrm{e}-14$ & -0.9142 & -0.9142 & -0.8127 & -0.8127 & $6.00 \mathrm{e}-15$ & -0.8127 & -0.8127 \\
\hline HTOA & -4.5485 & -0.6581 & 0.0521 & -2.6541 & -0.2657 & -2.5008 & -2.6881 & 0.6545 & -08365 & -0.6371 \\
\hline \multirow[t]{2}{*}{ LTOA } & -4.8905 & -4.0619 & $1.29 \mathrm{e}-13$ & -3.3545 & -0.3513 & -2.3052 & -2.9341 & 0.7805 & -0.9705 & -0.7385 \\
\hline & \multicolumn{5}{|c|}{$F 23$} & \multicolumn{5}{|c|}{ FOO } \\
\hline WOA & -5.0517 & -5.1273 & 0.3852 & -5.1273 & -1.3220 & 0.0000 & 0.0000 & 0.0000 & 0.0000 & 0.0000 \\
\hline TOA & -1.4705 & -1.4705 & $1.11 \mathrm{e}-14$ & -1.4705 & -1.4705 & 0.0000 & 0.0000 & 0.0000 & 0.0000 & 0.0000 \\
\hline HTOA & -1.0541 & -1.2210 & $1.54 \mathrm{e}-13$ & -1.4485 & -0.4165 & 0.0000 & 0.0000 & 0.0000 & 0.0000 & 0.0000 \\
\hline LTOA & -1.7451 & -1.8904 & $2.68 \mathrm{e}+14$ & -0.0678 & -0.6044 & 0.0000 & 0.0000 & 0.0000 & 0.0000 & 0.0000 \\
\hline
\end{tabular}

$\sigma_{\mu}=\left\{\frac{\cdots(1+\beta) \times \sin (\pi \times \beta / 1)}{\left.\cdots(1+\beta / 2) \times \beta \times 2^{(\beta-1) / 2}\right)}\right\}^{1 / \beta}$

where $u \sim N\left(0, \sigma_{\mu}{ }^{2}\right)$ and $v \sim N\left(0, \sigma_{v}{ }^{2}\right)$ are drawn from normal stochastic distributions. $\sigma_{v}=$ 1, the notation for $\sigma_{\mu}$ is presented in Eq. (15). Where “(.) denotes the Gamma function. The mathematical expression for " (.) is presented in Eq. (16).

$c(1+\beta)=\int_{0}^{\infty} t^{\beta} e^{-t} d t$ 
Table 6. Mean and Standard deviation (Std_Dev.) for 10 well-known datasets over 30 independent runs for 500 iterations

\begin{tabular}{|c|c|c|c|c|c|c|}
\hline \multirow[b]{2}{*}{ Alg. } & \multicolumn{3}{|c|}{ Iris_Dataset } & \multicolumn{3}{|c|}{ Glass_Dataset } \\
\hline & Solutioncost & Intra-cluster & $\begin{array}{l}\text { Inter- } \\
\text { cluster }\end{array}$ & Solution_cost & $\begin{array}{l}\text { Intra- } \\
\text { cluster }\end{array}$ & Inter-cluster \\
\hline $\mathrm{DE}$ & $0.279 \pm 0.0151$ & $2.241 \pm 0.3918$ & $\begin{array}{l}1.922 \pm \\
0.2778\end{array}$ & $0.058 \pm 0.0027$ & $\begin{array}{l}5.211 \pm \\
0.8509\end{array}$ & $\begin{array}{l}4.774 \pm \\
9.2009\end{array}$ \\
\hline PSO & $0.279 \pm 0.015$ & $2.470 \pm 0.3725$ & $\begin{array}{l}1.970 \pm \\
0.2784\end{array}$ & $0.043 \pm 0.0047$ & $\begin{array}{l}5.022 \pm \\
0.7034\end{array}$ & $\begin{array}{l}6.002 \pm \\
7.3475\end{array}$ \\
\hline WOA & $0.268 \pm 0.014$ & $2.390 \pm 0.3562$ & $\begin{array}{l}1.929 \pm \\
0.2789\end{array}$ & $0.044 \pm 0.0042$ & $\begin{array}{l}5.021 \pm \\
0.7014\end{array}$ & $\begin{array}{l}4.781 \pm \\
9.2109\end{array}$ \\
\hline CSAWOA & $0.268 \pm 0.007$ & $2.226 \pm 0.3429$ & $\begin{array}{l}1.962 \pm \\
0.2731\end{array}$ & $0.044 \pm 0.0029$ & $\begin{array}{l}4.878 \pm \\
0.8924\end{array}$ & $\begin{array}{l}6.008 \pm \\
7.3125\end{array}$ \\
\hline RWOA & $0.269 \pm 9.6 \mathrm{e}-4$ & $2.122 \pm 0.3522$ & $\begin{array}{l}1.980 \pm \\
0.2189\end{array}$ & $0.043 \pm 0.0017$ & $\begin{array}{l}4.875 \pm \\
0.8957\end{array}$ & $\begin{array}{l}6.419 \pm \\
6.9702\end{array}$ \\
\hline MSWOA & $0.266 \pm 0.0067$ & $2.064 \pm 0.3434$ & $\begin{array}{l}1.929 \pm \\
0.2789\end{array}$ & $0.043 \pm 0.0031$ & $\begin{array}{l}4.093 \pm \\
0.7134\end{array}$ & $\begin{array}{l}6.720 \pm \\
9.0704\end{array}$ \\
\hline HWOA & $0.264 \pm 0.0064$ & $2.018 \pm 0.3427$ & $\begin{array}{l}1.980 \pm \\
0.2189\end{array}$ & $0.041 \pm 0.0014$ & $\begin{array}{l}4.371 \pm \\
0.7447\end{array}$ & $\begin{array}{l}6.761 \pm \\
6.4308\end{array}$ \\
\hline TOA & $0.263 \pm 9.6 \mathrm{e}-4$ & $2.192 \pm 0.0512$ & $\begin{array}{l}1.980 \pm \\
0.2189\end{array}$ & $0.041 \pm 0.0017$ & $\begin{array}{l}4.874 \pm \\
0.8957\end{array}$ & $\begin{array}{l}6.419 \pm \\
6.9702\end{array}$ \\
\hline CTOA & $0.260 \pm 8.7 \mathrm{e}-4$ & $2.128 \pm 0.0503$ & $\begin{array}{l}1.924 \pm \\
0.2403\end{array}$ & $0.041 \pm 0.0021$ & $\begin{array}{l}4.868 \pm \\
0.4907\end{array}$ & $\begin{array}{l}5.940 \pm \\
2.1643\end{array}$ \\
\hline HTOA & $0.260 \pm 0.0005$ & $2.116 \pm 0.0442$ & $\begin{array}{l}1.974 \pm \\
0.2325\end{array}$ & $0.040 \pm 0.0021$ & $\begin{array}{l}4.360 \pm \\
0.4291\end{array}$ & $\begin{array}{l}6.452 \pm \\
3.1063\end{array}$ \\
\hline LTOA & $0.259 \pm 6.4 \mathrm{e}-4$ & $2.113 \pm 0.0545$ & $\begin{array}{l}1.907 \pm \\
0.2605\end{array}$ & $0.042 \pm 0.0045$ & $\begin{array}{l}4.336 \pm \\
0.4587\end{array}$ & $\begin{array}{l}6.610 \pm \\
4.8853\end{array}$ \\
\hline \multirow{2}{*}{ Alg. } & \multicolumn{3}{|c|}{ Wine_Dataset } & \multicolumn{3}{|c|}{ Breast_Dataset } \\
\hline & Solution_cost & Intra-cluster & Inter-cluster & Solution_cost & Intra-cluster & Inter-cluster \\
\hline $\mathrm{DE}$ & $359.416 \pm 11.105$ & $362.001 \pm 9.8672$ & $\begin{array}{l}359.827 \\
\pm \quad 54.460\end{array}$ & $0.062 \pm 0.0275$ & $\begin{array}{l}16.972 \pm \\
7.46 \mathrm{e}-15\end{array}$ & $13.4654 \pm 0$ \\
\hline PSO & $\begin{array}{l}343.838 \pm \\
3.5681\end{array}$ & $350.197 \pm 7.5448$ & $\begin{array}{l}349.746 \pm \\
46.731\end{array}$ & $0.056 \pm 0.0361$ & $\begin{array}{l}17.035 \pm \\
8.01 \mathrm{e}-15\end{array}$ & $13.5438 \pm 0$ \\
\hline WOA & $\begin{array}{l}340.112 \pm \\
10.929\end{array}$ & $350.195 \pm 7.5439$ & $\begin{array}{l}329.246 \pm \\
71.920\end{array}$ & $0.056 \pm 0.0285$ & $\begin{array}{l}17.025 \pm \\
7.95 \mathrm{e}-15\end{array}$ & $13.4529 \pm 0$ \\
\hline CSAWOA & $\begin{array}{l}342.838 \pm \\
3.6219\end{array}$ & $341.001 \pm 9.8928$ & $\begin{array}{l}363.784 \\
\pm \quad 46.720\end{array}$ & $0.055 \pm 0.0341$ & $\begin{array}{l}17.024 \pm \\
7.89 \mathrm{e}-15\end{array}$ & $13.4523 \pm 0$ \\
\hline RWOA & $341.7 \pm 6.8 \mathrm{e}-14$ & $332.792 \pm 2.2318$ & $\begin{array}{r}359.871 \\
\pm \quad 52.321\end{array}$ & $0.055 \pm 6.8 \mathrm{e}-4$ & $\begin{array}{l}16.980 \pm \\
7.45 \mathrm{e}-15\end{array}$ & $13.5521 \pm 0$ \\
\hline MSWOA & $341.63 \pm 1.6702$ & $330.104 \pm 7.4414$ & $\begin{array}{l}345.212 \\
\pm \quad 47.304\end{array}$ & $0.055 \pm 0.1385$ & $\begin{array}{l}16.042 \pm \\
7.75 \mathrm{e}-15\end{array}$ & $13.4521 \pm 0$ \\
\hline HWOA & $339.638 \pm 1.6716$ & $330.118 \pm 7.4034$ & $\begin{array}{l}329.271 \\
\pm \quad 47.916\end{array}$ & $0.053 \pm 0.0234$ & $\begin{array}{l}16.403 \pm \\
7.71 \mathrm{e}-15\end{array}$ & $13.4520 \pm 0$ \\
\hline TOA & $336.7 \pm 6.8 \mathrm{e}-14$ & $332.792 \pm 2.2318$ & $\begin{array}{l}359.871 \pm \\
52.324\end{array}$ & $0.052 \pm 6.8 \mathrm{e}-4$ & $\begin{array}{l}16.980 \pm \\
7.45 \mathrm{e}-15\end{array}$ & $13.5521 \pm 0$ \\
\hline
\end{tabular}


Table 6. Continued

\begin{tabular}{|c|c|c|c|c|c|c|}
\hline \multirow[b]{2}{*}{ Alg. } & \multicolumn{3}{|c|}{ Iris_Dataset } & \multicolumn{3}{|c|}{ Glass_Dataset } \\
\hline & Solutioncost & Intra-cluster & $\begin{array}{l}\text { Inter- } \\
\text { cluster }\end{array}$ & Solution_cost & $\begin{array}{l}\text { Intra- } \\
\text { cluster }\end{array}$ & Inter-cluster \\
\hline CTOA & $335.2 \pm 5.9 \mathrm{e}-14$ & $\begin{array}{l}330.307 \pm 8 \\
1084\end{array}$ & $\begin{array}{l}345.149 \pm \\
14.335\end{array}$ & $0.051 \pm 0.0248$ & $\begin{array}{l}16.670 \pm \\
7.31 \mathrm{e}-15\end{array}$ & $13.3417 \pm 0$ \\
\hline HTOA & $340.2 \pm 4.5 \mathrm{e}-14$ & $330.215 \pm 6.5457$ & $\begin{array}{l}345.054 \\
\pm \quad 35.740\end{array}$ & $0.051 \pm 0.0182$ & $\begin{array}{l}16.640 \pm \\
7.35 e-15\end{array}$ & $13.4055 \pm 0$ \\
\hline LTOA & $337.36 \pm 6.5 e-14$ & $331.053 \pm 2.2494$ & $\begin{array}{l}360.909 \pm \\
74.601\end{array}$ & $0.051 \pm 5.4 \mathrm{e}-4$ & $\begin{array}{l}16.600 \pm \\
7.17 \mathrm{e}-15\end{array}$ & $13.6782 \pm 0$ \\
\hline \multirow{2}{*}{ Alg. } & \multicolumn{3}{|c|}{ Diabetes_Dataset } & \multicolumn{3}{|c|}{ Haberman_Dataset } \\
\hline & Solution_cost & Intra-cluster & Inter-cluster & Solution_cost & Intra-cluster & Inter-cluster \\
\hline $\mathrm{DE}$ & $\begin{array}{l}14.5701 \pm \\
0.1814\end{array}$ & $\begin{array}{l}713.664 \pm \\
74.3624\end{array}$ & $\begin{array}{l}36.2192 \pm \\
12.246\end{array}$ & $5.5629 \pm 0.2713$ & $\begin{array}{l}35.108 \pm \\
3.5591\end{array}$ & $\begin{array}{l}8.736 \pm \\
10.813\end{array}$ \\
\hline PSO & $\begin{array}{l}14.4416 \pm \\
0.0548\end{array}$ & $\begin{array}{l}713.650 \pm \\
74.3512\end{array}$ & $\begin{array}{l}36.2192 \pm \\
12.240\end{array}$ & $5.7000 \pm 0.3045$ & $\begin{array}{l}35.345 \pm \\
3.6982\end{array}$ & $\begin{array}{l}7.355 \pm \\
9.8732\end{array}$ \\
\hline WOA & $\begin{array}{l}14.2800 \pm \\
0.1654\end{array}$ & $\begin{array}{l}708.013 \pm \\
74.4521\end{array}$ & $\begin{array}{l}36.2301 \pm \\
14.773\end{array}$ & $5.7700 \pm 0.2845$ & $\begin{array}{l}35.303 \pm \\
3.6534\end{array}$ & $\begin{array}{l}7.642 \pm \\
9.8043\end{array}$ \\
\hline CSAWOA & $\begin{array}{l}13.8524 \pm \\
0.0459\end{array}$ & $\begin{array}{l}705.981 \pm \\
74.3714\end{array}$ & $\begin{array}{l}36.8004 \pm \\
14.454\end{array}$ & $5.3300 \pm 0.3545$ & $\begin{array}{l}35.206 \pm \\
3.0475\end{array}$ & $\begin{array}{l}7.982 \pm \\
9.9801\end{array}$ \\
\hline RWOA & $\begin{array}{l}13.7689 \pm \\
0.0025\end{array}$ & $\begin{array}{l}705.980 \pm \\
74.3512\end{array}$ & $\begin{array}{l}36.8425 \pm \\
14.451\end{array}$ & $5.5689 \pm 3.6 \mathrm{e}-6$ & $\begin{array}{l}34.988 \pm \\
3.6875\end{array}$ & $\begin{array}{l}8.129 \pm \\
10.422\end{array}$ \\
\hline MSWOA & $\begin{array}{l}13.7741 \pm \\
0.0454\end{array}$ & $\begin{array}{l}705.016 \pm \\
74.6151\end{array}$ & $\begin{array}{l}36.3051 \pm \\
14.351\end{array}$ & $5.3655 \pm 0.3065$ & $\begin{array}{l}34.372 \pm \\
3.5504\end{array}$ & $\begin{array}{l}7.305 \pm \\
9.8042\end{array}$ \\
\hline HWOA & $\begin{array}{l}13.7453 \pm \\
0.0656\end{array}$ & $\begin{array}{l}705.004 \pm \\
74.3402\end{array}$ & $\begin{array}{l}36.3801 \pm \\
14.346\end{array}$ & $5.2814 \pm 0.3061$ & $\begin{array}{l}34.312 \pm \\
3.5530\end{array}$ & $\begin{array}{l}7.361 \pm \\
9.8342\end{array}$ \\
\hline TOA & $\begin{array}{l}14.4523 \pm \\
0.0025\end{array}$ & $\begin{array}{l}705.980 \pm \\
74.3512\end{array}$ & $\begin{array}{l}36.8425 \pm \\
14.451\end{array}$ & $4.9842 \pm 3.6 \mathrm{e}-6$ & $\begin{array}{l}34.988 \pm \\
3.6875\end{array}$ & $\begin{array}{l}8.128 \pm \\
10.422\end{array}$ \\
\hline CTOA & $\begin{array}{l}14.0013 \pm \\
0.1501\end{array}$ & $\begin{array}{l}705.150 \\
\pm 74.3501\end{array}$ & $\begin{array}{l}36.8183 \\
\pm 14.450\end{array}$ & $5.3901 \pm 3.6 \mathrm{e}-6$ & $\begin{array}{l}34.816 \pm \\
3.6002\end{array}$ & $\begin{array}{l}8.081 \pm \\
9.9723\end{array}$ \\
\hline HTOA & $\begin{array}{l}13.5131 \pm \\
0.4228\end{array}$ & $\begin{array}{l}705.352 \pm \\
16.4868\end{array}$ & $\begin{array}{l}36.6105 \pm \\
14.641\end{array}$ & $5.1901 \pm 3.6 \mathrm{e}-6$ & $\begin{array}{l}34.802 \pm \\
3.6812\end{array}$ & $\begin{array}{l}7.814 \pm \\
9.5508\end{array}$ \\
\hline LTOA & $\begin{array}{l}13.4348 \pm \\
0.5105\end{array}$ & $\begin{array}{l}705.327 \pm \\
72.9391\end{array}$ & $\begin{array}{l}36.6008 \pm \\
14.330\end{array}$ & $5.1884 \pm 3.7 \mathrm{e}-6$ & $\begin{array}{l}34.053 \pm \\
3.0274\end{array}$ & $\begin{array}{l}7.054 \pm \\
9.3142\end{array}$ \\
\hline \multirow{2}{*}{ Alg. } & \multicolumn{3}{|c|}{ Hayes-Roth_Dataset } & \multicolumn{3}{|c|}{ E. Coli_Dataset } \\
\hline & Solution_cost & Intra-cluster & Inter-cluster & Solution_cost & Intra-cluster & Inter-cluster \\
\hline $\mathrm{DE}$ & $0.3928 \pm 0.0346$ & $3.518 \pm 0.2735$ & $\begin{array}{l}1.8519 \pm \\
0.7531\end{array}$ & $0.0663 \pm 0.0032$ & $\begin{array}{l}0.6643 \pm \\
0.0735\end{array}$ & $\begin{array}{l}0.3637 \pm \\
0.1341\end{array}$ \\
\hline PSO & $0.3507 \pm 0.0254$ & $3.5081 \pm 0.4318$ & $\begin{array}{l}1.4189 \pm \\
0.6078\end{array}$ & $0.0671 \pm 0.0030$ & $\begin{array}{l}0.6312 \pm \\
0.0726\end{array}$ & $\begin{array}{l}0.3145 \pm \\
0.1028\end{array}$ \\
\hline WOA & $0.3672 \pm 0.0284$ & $3.5492 \pm 0.4865$ & $\begin{array}{l}1.4256 \pm \\
0.6845\end{array}$ & $0.0641 \pm 0.0028$ & $\begin{array}{l}0.6745 \pm \\
0.0825\end{array}$ & $\begin{array}{l}0.3176 \pm \\
0.1517\end{array}$ \\
\hline CSAWOA & $0.2681 \pm 0.0248$ & $3.5413 \pm 0.4716$ & $\begin{array}{l}1.7012 \pm \\
0.6146\end{array}$ & $0.0666 \pm 0.0030$ & $\begin{array}{l}0.6245 \pm \\
0.0689\end{array}$ & $\begin{array}{l}0.4540 \pm \\
0.1056\end{array}$ \\
\hline
\end{tabular}


Table 6. Continued

\begin{tabular}{|c|c|c|c|c|c|c|}
\hline \multirow[b]{2}{*}{ Alg. } & \multicolumn{3}{|c|}{ Iris_Dataset } & \multicolumn{3}{|c|}{ Glass_Dataset } \\
\hline & Solutioncost & Intra-cluster & $\begin{array}{l}\text { Inter- } \\
\text { cluster }\end{array}$ & Solution_cost & $\begin{array}{l}\text { Intra- } \\
\text { cluster }\end{array}$ & Inter-cluster \\
\hline RWOA & $0.2689 \pm 0.0129$ & $3.2508 \pm 0.3512$ & $\begin{array}{l}1.8251 \pm \\
0.6702\end{array}$ & $0.0641 \pm 0.0012$ & $\begin{array}{l}0.6012 \pm \\
0.0542\end{array}$ & $\begin{array}{l}0.4643 \pm \\
0.1728\end{array}$ \\
\hline MSWOA & $0.2655 \pm 0.0105$ & $3.3415 \pm 0.4181$ & $\begin{array}{l}1.4046 \pm \\
0.6451\end{array}$ & $0.0637 \pm 0.0012$ & $\begin{array}{l}0.6015 \pm \\
0.0621\end{array}$ & $\begin{array}{l}0.3206 \pm \\
0.1410\end{array}$ \\
\hline HWOA & $0.2645 \pm 0.0108$ & $3.5472 \pm 0.4160$ & $\begin{array}{l}1.4053 \pm \\
0.6415\end{array}$ & $0.0624 \pm 0.0011$ & $\begin{array}{l}0.6018 \pm \\
0.0721\end{array}$ & $\begin{array}{l}0.3603 \pm \\
0.1421\end{array}$ \\
\hline TOA & $0.2418 \pm 0.0129$ & $3.2508 \pm 0.3512$ & $\begin{array}{l}1.8251 \pm \\
0.6702\end{array}$ & $0.0558 \pm 0.0012$ & $\begin{array}{l}0.6012 \pm \\
0.0542\end{array}$ & $\begin{array}{l}0.4643 \pm \\
0.1728\end{array}$ \\
\hline CTOA & $0.2381 \pm 0.0148$ & $3.2518 \pm 0.3414$ & $\begin{array}{l}1.4108 \pm \\
0.5168\end{array}$ & $0.0553 \pm 0.0031$ & $\begin{array}{l}0.5981 \pm \\
0.0601\end{array}$ & $\begin{array}{l}0.3501 \pm \\
0.0918\end{array}$ \\
\hline HTOA & $0.2514 \pm 0.0134$ & $3.2415 \pm 0.3251$ & $\begin{array}{l}1.4206 \pm \\
0.6105\end{array}$ & $0.0545 \pm 0.0018$ & $\begin{array}{l}0.6003 \pm \\
0.0567\end{array}$ & $\begin{array}{l}0.3164 \pm \\
0.1306\end{array}$ \\
\hline LTOA & $0.2467 \pm 0.0478$ & $3.2574 \pm 0.3625$ & $\begin{array}{l}1.5624 \pm \\
0.6701\end{array}$ & $0.0544 \pm 0.0054$ & $\begin{array}{l}0.5997 \pm \\
0.0418\end{array}$ & $\begin{array}{l}0.3481 \pm \\
0.1907\end{array}$ \\
\hline \multirow{2}{*}{ Alg. } & \multicolumn{3}{|c|}{ Zoo_Dataset } & \multicolumn{3}{|c|}{ Vowel_Dataset } \\
\hline & Solution_cost & Intra-cluster & Inter-cluster & Solutioncost & Intra-cluster & Inter-cluster \\
\hline $\mathrm{DE}$ & $0.0220 \pm 0.0024$ & $1.6512 \pm 1.1 \mathrm{e}-15$ & $\begin{array}{l}2.6502 \pm \\
2.3 e-15\end{array}$ & $\begin{array}{l}39.2800 \pm \\
2.2481\end{array}$ & $\begin{array}{l}898.617 \pm \\
102.946\end{array}$ & $\begin{array}{l}353.3712 \pm \\
218.25\end{array}$ \\
\hline PSO & $0.0130 \pm 0.0018$ & $1.6396 \pm 1.1 \mathrm{e}-15$ & $\begin{array}{l}2.6421 \pm \\
2.3 \mathrm{e}-15\end{array}$ & $\begin{array}{l}38.4700 \pm \\
2.3618\end{array}$ & $\begin{array}{l}899.254 \pm \\
101.895\end{array}$ & $\begin{array}{l}350.3465 \pm \\
215.71\end{array}$ \\
\hline WOA & $0.0120 \pm 0.0022$ & $1.6401 \pm 1.1 \mathrm{e}-15$ & $\begin{array}{l}2.6471 \pm \\
2.3 e-15\end{array}$ & $\begin{array}{l}38.4012 \pm \\
2.2314\end{array}$ & $\begin{array}{l}899.246 \pm \\
101.871\end{array}$ & $\begin{array}{l}350.3548 \pm \\
215.65\end{array}$ \\
\hline CSAWOA & $0.0090 \pm 0.0019$ & $1.6381 \pm 1.1 \mathrm{e}-15$ & $\begin{array}{l}2.6487 \pm \\
2.3 e-15\end{array}$ & $\begin{array}{l}36.8140 \pm \\
2.3456\end{array}$ & $\begin{array}{l}899.228 \pm \\
102.382\end{array}$ & $\begin{array}{l}350.8086 \pm \\
215.95\end{array}$ \\
\hline RWOA & $0.0094 \pm 8.4-04$ & $1.5254 \pm 4.5 \mathrm{e}-16$ & $\begin{array}{l}2.6502 \pm \\
2.3 e-15\end{array}$ & $\begin{array}{l}35.8941 \pm \\
2.2145\end{array}$ & $\begin{array}{l}898.145 \pm \\
102.982\end{array}$ & $\begin{array}{l}353.3282 \pm \\
218.25\end{array}$ \\
\hline MSWOA & $0.0100 \pm 0.0012$ & $1.5332 \pm 1.1 \mathrm{e}-14$ & $\begin{array}{l}2.6451 \pm \\
2.3 e-15\end{array}$ & $\begin{array}{l}34.1553 \pm \\
2.2645\end{array}$ & $\begin{array}{l}898.224 \pm \\
102.314\end{array}$ & $\begin{array}{l}350.7301 \pm \\
215.96\end{array}$ \\
\hline HWOA & $0.0053 \pm 0.0024$ & $1.4301 \pm 1.1 \mathrm{e}-14$ & $\begin{array}{l}2.6432 \pm \\
2.3 \mathrm{e}-15\end{array}$ & $\begin{array}{l}32.4501 \pm \\
2.2416\end{array}$ & $\begin{array}{l}898.138 \pm \\
102.311\end{array}$ & $\begin{array}{l}350.6126 \pm \\
215.94\end{array}$ \\
\hline TOA & $0.0102 \pm 8.4-04$ & $1.5254 \pm 4.5 \mathrm{e}-16$ & $\begin{array}{l}2.6502 \pm \\
2.3 \mathrm{e}-15\end{array}$ & $\begin{array}{l}30.2145 \pm \\
2.2145\end{array}$ & $\begin{array}{l}898.145 \pm \\
102.982\end{array}$ & $\begin{array}{l}353.3282 \pm \\
218.25\end{array}$ \\
\hline CTOA & $0.0113 \pm 0.0023$ & $1.6506 \pm 1.1 \mathrm{e}-15$ & $\begin{array}{l}2.6142 \pm \\
2.3 e-15\end{array}$ & $\begin{array}{l}30.0018 \pm \\
2.0604\end{array}$ & $\begin{array}{l}894.627 \pm \\
101.692\end{array}$ & $\begin{array}{l}353.1527 \pm \\
218.04\end{array}$ \\
\hline HTOA & $0.0120 \pm 0.3581$ & $1.3418 \pm 2.1 \mathrm{e}-16$ & $\begin{array}{l}2.6105 \pm \\
2.3 e-15\end{array}$ & $\begin{array}{l}29.9971 \pm \\
2.0491\end{array}$ & $\begin{array}{l}895.455 \pm \\
101.385\end{array}$ & $\begin{array}{l}353.6101 \pm \\
218.69\end{array}$ \\
\hline LTOA & $0.0127 \pm 4.3 \mathrm{e}-04$ & $1.3415 \pm 0.4 \mathrm{e}-16$ & $\begin{array}{l}2.4153 \pm \\
0.6 \mathrm{e}-15\end{array}$ & $\begin{array}{l}30.6404 \pm \\
2.4058\end{array}$ & $\begin{array}{l}895.347 \pm \\
101.870\end{array}$ & $\begin{array}{l}352.0457 \pm \\
215.67\end{array}$ \\
\hline
\end{tabular}


Table 7. The detailed system configuration

\begin{tabular}{|l|l|}
\hline Name & Configuration \\
\hline Hardware & \\
\hline CPU & $\begin{array}{l}\text { Intel(R) } \\
\text { Core(TM)-i5-2400 }\end{array}$ \\
\hline Clock Rate & $3.10 \mathrm{GHz}$ \\
\hline RAM & $8 \mathrm{~GB}$ \\
\hline Hard Disc & $500 \mathrm{~GB}$ \\
\hline Software & \\
\hline OS & Windows 7 Home \\
\hline Programming tool & MATLAB-R2016a \\
\hline
\end{tabular}

Summarized the main steps of LTOA in the pseudo code as shown in Table 4. Flowchart of the LTOA is presented in Fig. 2.

\section{EXPERIMENTAL ANALYSIS}

This section focuses on the performance evaluation of the Lévy flight TOA (LTOA) algorithm using different complex function optimization problems. In order to obtain an unbiased comparison of acquired results, each and every experiment is done on the same system which have the configuration detailed in Table 8 . The primary objective of this work is to design an advanced clustering approach for solving different cluster problems. Before achieving this objective, the function optimization performance of proposed hybrid version of the standard TOA is tested. This was denoted as phase one in this work, wherein the second phase solved data cluster problems.

\section{Phase I: Benchmark Function Problems}

Several experiments are conducted to evaluate the performance of the proposed Lévy flight TOA algorithm. The twenty three well-known mathematical functions with a variety of complexity are considered in performance evaluation process. These benchmark functions comprises 7 Unimodal (F1 to F7), 6 Multimodal (F8 to F13) and 10 fixed dimension (F14 to F23) and notations of these functions are presented in Table 1, 2 and 3. The obtained results of proposed LTOA are compared with WOA, TOA, and HTOA (Hybrid TOA using BBBC). Five statistical metrics (Median, Standard Deviation (Std. Dev), Minimum (Best) and Maximum (Worst)) are used in result comparison and these statistical analysis are portrayed in Table 6. From the Table 6, it clearly shows, for unimodal functionsF1, F3, F4, F5, F6 and F7 exhibits the improved performance when compared to other existing algorithms. The LTOA exhibits the improved performance for functions F9, F10, F11, F15, F15, F18, F19 and F21 of Multimodal and fixed dimension function problems.

\section{Phase II: Clustering Problems}

This phase presents the performance evaluation of the proposed Lévy TOA based clustering approach. Part of performance evaluation, several investigations are carried out in solving 10 UCI data cluster problems and 4 Web Document Cluster problems. Any good clustering approach minimizes the quantization error; presented in Eq. (1) for the taken input data cluster problems. To investigate the performance of the proposed clustering approach in this paper, 10 different clustering problems are taken. The statistical measures like mean (Average) and standard deviation (Std. Dev) are considered 
Table 8. Ground-truth validation results

\begin{tabular}{|c|c|c|c|c|c|c|c|}
\hline \multirow[t]{5}{*}{ Precision } & Dataset & $\begin{array}{l}\text { WDC- } \\
\text { CSK } \\
\text { BBIC }\end{array}$ & HWOA & TOA & CTOA & HTOA & LTOA \\
\hline & DMOZ-50 & 89.51 & 89.52 & 90.07 & 90.11 & 88.15 & 90.13 \\
\hline & AMBIENT & 77.71 & 77.69 & 78.00 & 78.65 & 78.33 & 78.16 \\
\hline & MORESQUE & 88.16 & 88.35 & 87.91 & 87.93 & 87.93 & 88.84 \\
\hline & $O D P-239$ & 59.58 & 56.07 & 59.15 & 60.51 & 60.68 & 60.71 \\
\hline \multirow[t]{5}{*}{ Recall } & Dataset & $\begin{array}{l}\text { WDC- } \\
\text { CSK } \\
\text { BBIC }\end{array}$ & HWOA & TOA & CTOA & HTOA & LTOA \\
\hline & DMOZ-50 & 75.92 & 75.35 & 76.64 & 68.51 & 73.68 & 76.66 \\
\hline & AMBIENT & 59.06 & 56.61 & 58.45 & 61.31 & 61.01 & 59.85 \\
\hline & MORESQUE & 39.99 & 40.01 & 40.01 & 41.24 & 40.26 & 41.05 \\
\hline & $O D P-239$ & 44.77 & 44.84 & 41.65 & 43.54 & 45.37 & 43.55 \\
\hline \multirow[t]{5}{*}{ F-measure } & Dataset & $\begin{array}{l}\text { WDC- } \\
\text { CSK } \\
\text { BBIC }\end{array}$ & HWOA & TOA & CTOA & HTOA & LTOA \\
\hline & DMOZ-50 & 80.10 & 80.01 & 80.00 & 81.81 & 80.64 & 79.81 \\
\hline & AMBIENT & 62.02 & 61.05 & 62.61 & 62.24 & 60.64 & 63.02 \\
\hline & MORESQUE & 49.89 & 49.90 & 50.03 & 50.03 & 50.71 & 51.06 \\
\hline & $O D P-239$ & 46.37 & 46.38 & 46.41 & 47.08 & 47.14 & 47.14 \\
\hline \multirow[t]{5}{*}{ Accuracy } & Dataset & $\begin{array}{l}\text { WDC- } \\
\text { CSK } \\
\text { BBIC }\end{array}$ & HWOA & TOA & CTOA & HTOA & LTOA \\
\hline & DMOZ-50 & 93.45 & 91.38 & 94.06 & 94.17 & 94.06 & 94.17 \\
\hline & AMBIENT & 82.88 & 82.96 & 83.44 & 82.91 & 82.30 & 82.91 \\
\hline & MORESQUE & 58.82 & 57.91 & 58.60 & 58.35 & 58.91 & 58.46 \\
\hline & $O D P-239$ & 81.90 & 82.51 & 82.06 & 82.39 & 82.26 & 82.67 \\
\hline
\end{tabular}

in comparisons. Obtained clustering results of proposed LTOA based clustering approach are compared with the results obtained for other optimization algorithm based clustering approaches (DE (Differential Evolution), PSO, WOA,CSAWOA (Clonal Selection Algorithm WOA), RWOA (Ring WOA), MSWOA (Master-Slave WOA), HWOA (Hybrid WOA), TOA, CTOA (Chaotic TOA) and HTOA) for the same datasets. Table 7 presents the Mean and Std_Dev values over number of independent runs: 30 for number of iterations: 500. It is observed from the Table 7 that for the Iris dataset, the proposed LTOA based cluster approach obtains the lower solution cost. The mean and standard deviation of the solution cost for the Iris dataset are 0.2591 and $6.3733 \mathrm{e}-004$ respectively. Proposed method achieves the best clusters for the other datasets wine, Breast, Piama Indian Diabetes, Haberman, Hayes-Roth and E. Coli with the low solution costs. For the remaining datasets the clustering performance is almost close to the other existing clustering approaches. From the obtained statistical and graphical results presented in Table 7 and Fig. 3, the proposed LTOA based clustering approach demonstrated to be superior compared to other well-known algorithms. 
Four web document clustering problems also used in this paper to test the numerical complexity of proposed LTOA based clustering approach. Four ground-truth validation techniques Precision, Recall, F-measure and Accuracy are used. These validation

results for minimizing the quantization error presented in Eq. (1) are portrayed in Table 8.The comparisons have been made to LTOA with other existing web document clustering problem solving clustering approaches WDC-CSK BBIC, HWOA, TOA, CTOA and HTOA.From the Table 8, the proposed clustering approach is working well for DMOZ-50, MORESQUE and ODP-239. For the dataset AMBIENT, Proposed clustering approach gives the results which are very much closer to the other existing methods.

\section{CONCLUSION AND FUTURE WORK}

In this research work, as primary goal a novel clustering approach was designed by conjoining the traditional clustering algorithm and Lévy flight TOA for solving different data cluster problems which were taken from various sources. The standard TOA is hybridized with Lévy flight trajectory algorithm for enhancing the standard TOA in global function optimization perspective. The simulation of experiments was done in two phases. In the first phase hybrid version of the TOA is benchmarked on 23 mathematical function optimization problems. The comparative analysis of Lévy flight TOA has been made with well-known meta-heuristic methods. From the obtained statistical and graphical analysis, it is confirmed that the proposed hybrid TOA quickly converges to optimal solutions for the majority of the input test functions. Where in the second phase, the numerical complexity of proposed novel clustering approach was done by assessing on 14 different cluster problems which include 10 UCI cluster problems and 4 Web Document Cluster problems. The performance evaluation metrics: solution cost, intra-cluster and inter-cluster distances were used and compared the obtained graphical statistical results with other existed clustering approaches. For the web document cluster problems the ground-truth validation metrics: precision, recall, F-measure and accuracy were used. The simulation experiments and analysis, and conducted comparisons in the second phase acknowledge that the proposed Lévy flight TOA based novel clustering approach was fast and efficient in obtaining best clusters.

This research work primarily focussed on discovering Lévy flight trajectory based hybrid TOA for solving global function optimization problems as well as different data cluster problems. From the simulation experiments and analysis the proposed clustering approach is a suitable addition to clustering domains for solving complex data clustering problems. The NFL theorem logically proved that there is not any single optimization technique existed that can solve all sorts of optimization problems. In this work Lévy flight trajectory algorithm was used to enhance the standard TOA. In future work, other performance boosting up methods can be investigated. The future research also can development of new and novel nature-inspired Metaheuristics. 


\section{REFERENCES}

Azar, A. T., \& Vaidyanathan, S. (Eds.). (2015). Computational intelligence applications in modeling and control. Springer International Publishing.

Bouarara, H. A., Hamou, R. M., Rahmani, A., \& Amine, A. (2015). Boosting algorithm and meta-heuristic based on genetic algorithms for textual plagiarism detection. International Journal of Cognitive Informatics and Natural Intelligence, 9(4), 65-87.

Bouyer, A., \& Hatamlou, A. (2018). An efficient hybrid clustering method based on improved cuckoo optimization and modified particle swarm optimization algorithms. Applied Soft Computing, 67, 172-182.

Das, P., Das, D. K., \& Dey, S. (2018). A New Class Topper Optimization Algorithm with an Application to Data Clustering. IEEE Transactions on Emerging Topics in Computing.

Eberhart, R., \& Kennedy, J. (1995, October). A new optimizer using particle swarm theory. In Micro Machine and Human Science, 1995. MHS'95., Proceedings of the Sixth International Symposium on (pp. 39-43). IEEE.

Erol, O. K., \& Eksin, I. (2006). A new optimization method: Big bang-big crunch. Advances in Engineering Software, 37(2), 106-111.

Fister, I., Jr., Yang, X. S., Fister, I., Brest, J., \& Fister, D. (2013). A brief review of nature-inspired algorithms for optimization. arXiv preprint arXiv:1307.4186.

Gheraibia, Y., Moussaoui, A., Djenouri, Y., Kabir, S., Yin, P. Y., \& Mazouzi, S. (2015). Penguin search optimisation algorithm for finding optimal spaced seeds. International Journal of Software Science and Computational Intelligence, 7(2), 85-99.

Jacques, J., \& Preda, C. (2014). Functional data clustering: A survey. Advances in Data Analysis and Classification, $8(3), 231-255$.

James, J. Q., \& Li, V. O. (2015). A social spider algorithm for global optimization. Applied Soft Computing, $30,614-627$.

Jensi, R., \& Jiji, G. W. (2016). An enhanced particle swarm optimization with levy flight for global optimization. Applied Soft Computing, 43, 248-261.

José-García, A., \& Gómez-Flores, W. (2016). Automatic clustering using nature-inspired metaheuristics: A survey. Applied Soft Computing, 41, 192-213.

Kamaruzaman, A. F., Zain, A. M., Yusuf, S. M., \& Udin, A. (2013). Levy flight algorithm for optimization problems-a literature review. Applied Mechanics and Materials, 421, 496-501.

Kaynak, O., Zadeh, L. A., Türksen, B., \& Rudas, I. J. (Eds.). (2012). Computational intelligence: Soft computing and fuzzy-neuro integration with applications (Vol. 162). Springer Science \& Business Media.

Kriegel, H. P., Kröger, P., Sander, J., \& Zimek, A. (2011). Density-based clustering. Wiley Interdisciplinary Reviews. Data Mining and Knowledge Discovery, 1(3), 231-240.

Li, X., Zhang, J., \& Yin, M. (2014). Animal migration optimization: An optimization algorithm inspired by animal migration behavior. Neural Computing \& Applications, 24(7-8), 1867-1877.

Mirjalili, S. (2015). Moth-flame optimization algorithm: A novel nature-inspired heuristic paradigm. KnowledgeBased Systems, 89, 228-249.

Mirjalili, S., Gandomi, A. H., Mirjalili, S. Z., Saremi, S., Faris, H., \& Mirjalili, S. M. (2017). Salp Swarm Algorithm: A bio-inspired optimizer for engineering design problems. Advances in Engineering Software, 114, 163-191.

Mirjalili, S., \& Lewis, A. (2016). The whale optimization algorithm. Advances in Engineering Software, 95, 51-67.

Mirjalili, S., Mirjalili, S. M., \& Lewis, A. (2014). Grey wolf optimizer. Advances in Engineering Software, 69, 46-61. 
Murtagh, F. (1983). A survey of recent advances in hierarchical clustering algorithms. The Computer Journal, 26(4), 354-359.

Nagpal, A., Jatain, A., \& Gaur, D. (2013, April). Review based on data clustering algorithms. In Information \& Communication Technologies (ICT), 2013 IEEE Conference on (pp. 298-303). IEEE.

Nanda, S. J., \& Panda, G. (2014). A survey on nature inspired Metaheuristics algorithms for Partitional clustering. Swarm and Evolutionary Computation, 16, 1-18.

Nouaouria, N., Boukadoum, M., \& Proulx, R. (2014). A Particle Swarm Optimization Approach for Reuse Guided Case Retrieval. International Journal of Software Science and Computational Intelligence, 6(3), 16-30.

Pedrycz, W., Krawczak, M., \& Zadrożny, S. (2018). Computational intelligence techniques for decision support, data mining and information searching. Academic Press.

Saidala, R. K., \& Devarakonda, N. (2017c). Multi-Swarm Whale Optimization Algorithm for Data Clustering Problems using Multiple Cooperative Strategies. International Journal of Intelligent Systems and Applications.

Saidala, R. K., \& Devarakonda, N. (2017d). The Tornadogenesis optimization algorithm. In Cognitive Informatics \& Cognitive Computing (ICCI* CC), 2017 IEEE 16th International Conference on (pp. 378-387). IEEE.

Saidala, R. K., \& Devarakonda, N. (2018a). Improved Whale Optimization Algorithm Case Study: Clinical Data of Anaemic Pregnant Woman. In Data Engineering and Intelligent Computing (pp. 271-281). Springer.

Saidala, R. K., \& Devarakonda, N. (2018b). Chaotic Tornadogenesis Optimization Algorithm for Data Clustering Problems. International Journal of Software Science and Computational Intelligence, 10(1), 38-64.

Saidala, R. K., \& Devarakonda, N. (2018d). Northern Bald Ibis Optimization Algorithm: Theory and Application. In 2018 IEEE 17th International Conference on Cognitive Informatics \& Cognitive Computing (ICCI* CC) (pp. 541-551). IEEE.

Saidala, R. K., \& Devarakonda, N. (2018f). A Novel Chaotic Northern Bald Ibis Optimization Algorithm for Solving Different Cluster Problems. International Journal of Software Science and Computational Intelligence.

Saidala, R. K., Devarakonda, N., \& Edara, S. R. (2018e). Enhanced Northern Bald Ibis Optimization Algorithm based Clustering Method for Web Document Clustering. Journal of Advanced Research in Dynamical and Control Systems.

Saidala, R. K., Devarakonda, N., \& Kamaraiugadda, R. (2018c). Hybrid Air Mass Collision Based Optimization Algorithm for Data Cluster Problems. In 2018 IEEE 17th International Conference on Cognitive Informatics \& Cognitive Computing (ICCI*CC) (pp. 507-516). IEEE.

Saidala, R. K., \& Devarakonda, N. R. (2017a). A new parallel metaheuristic optimization algorithm and its application in CDM. In Convergence in Technology (I2CT), 2017 2nd International Conference for (pp. 667674). IEEE.

Saidala, R. K., \& Devarakonda, N. R. (2017b). Bubble-net hunting strategy of whales based optimized feature selection for e-mail classification. In Convergence in Technology (I2CT), 2017 2nd International Conference for (pp. 626-631). IEEE.

Schor, D., \& Kinsner, W. (2011). Time and frequency analysis of particle swarm trajectories for cognitive machines. International Journal of Cognitive Informatics and Natural Intelligence, 5(1), 18-42.

Wang, Y. (2017). On cognitive foundations and mathematical theories of knowledge science. In Artificial Intelligence: Concepts, Methodologies, Tools, and Applications (pp. 889-914). IGI Global.

Wang, Y., Widrow, B., Zadeh, L. A., Howard, N., Wood, S., Bhavsar, V. C., \& Shell, D. F. (2016). Cognitive intelligence: Deep learning, thinking, and reasoning by brain-inspired systems. International Journal of Cognitive Informatics and Natural Intelligence, 10(4), 1-20.

Witten, I. H., Frank, E., Hall, M. A., \& Pal, C. J. (2016). Data Mining: Practical machine learning tools and techniques. Morgan Kaufmann.

Xu, R., \& Wunsch, D. (2005). Survey of clustering algorithms. IEEE Transactions on Neural Networks, 16(3), 645-678. 
Xu, W., Zhou, H., Cheng, N., Lyu, F., Shi, W., Chen, J., \& Shen, X. (2017). Internet of vehicles in big data era. IEEE/CAA Journal of Automatica Sinica, 5(1), 19-35.

Zadeh, L. A. (1973). Outline of a new approach to the analysis of complex systems and decision processes. IEEE Transactions on Systems, Man, and Cybernetics, (1), 28-44.

Zadeh, L. A. (1996). Fuzzy logic, neural networks, and soft computing. In Fuzzy Sets, Fuzzy Logic, And Fuzzy Systems: Selected Papers by Lotfi A Zadeh (pp. 775-782). Academic Press.

Zadeh, L. A., Fu, K. S., \& Tanaka, K. (Eds.). (2014). Fuzzy sets and their applications to cognitive and decision processes: Proceedings of the us-japan seminar on fuzzy sets and their applications, held at the university of california, berkeley, california. Academic Press.

Dr. Nagaraju Devarakonda received his B. Tech. from Sri Venkateswara University, Tirupathi, M. Tech. from Jawaharlal Nehru University (JNU), New Delhi, and Ph.D. from Jawaharlal Nehru Technological University, Hyderabad. He has published over 80 research papers in International Conferences and Journals. He is the Editor of Proceedings of ICCIDE 2017 and 2018, 2020, 2021. The proceedings were published in Lecture Notes on Data Engineering and Communication Technologies of SPRINGER. He published papers in ICCI*CC 2017 at OXFORD UNIVERSITY, UK, ICCI ${ }^{*} C C 2018$ at UNIVERSITY OF CALIFORNIA, BERKELEY, USA, and ICCI ${ }^{*} C C 2019$ at POLITECNICO DI MILANO UNIVERSITY, MILAN, ITALY. He is currently working as an Associate Professor in the School of Computer Science \& Engineering at VIT-AP University, Andhra Pradesh, India and has 16 years of experience in teaching. His research areas are data mining, soft computing, machine learning and pattern recognition. He has supervised 25 M.Tech. students, guided 2 Ph.D.s and currently guiding 7 Ph.D.s. He is an Editorial Board member for various reputed international journals and reviewer for IEEE, Springer, ACM, and Elsevier Journals.

Dr. Ravi Kumar Saidala is currently working for KL Deemed to be University in department of Computer Science and Engineering as Assistant Professor. In 2020, he received his doctoral degree, Doctor of Philosophy with specialization Data Mining from Acharya Nagarjuna University, India. In 2013, he received his Master's degree, Master of Technology with specialization Computer Science and Engineering from Acharya Nagarjuna University, India. He secured 2nd top rank overall in the university in 2011-13 M-Tech batch. In 2011, he received Bachelor's degree, Bachelor of Technology from Jawaharlal Nehru Technological University Kakinada, India, in Computer Science and Engineering. Within the period of his doctoral-level studies at the Doctor of Philosophy of computer science and engineering, he has demonstrated himself extraordinary as disciplined and dedicated research scholar. As an unwavering dedicated researcher, he has published 20 research papers in various reputed Web of science, SCOPUS, DBLP, ACM Digital library indexed international journals and flagship international conferences like IEEE ICCI*CC'17, OXFORD UNIVERSITY, Oxford, UK and IEEE ICCI*CC'18, UNIVERSITY OF CALIFORNIA, Berkeley, USA. In 2014, he was selected for UGC National Fellowship programme. His doctoral research investigates the design and development of new nature inspired Metaheuristics, advanced optimum clustering methods which utilize optimization algorithms. He takes a multidisciplinary approach that encompasses the fields of Data Mining, Data Engineering, Machine Learning, Computational Intelligence and Digital Image Processing. He is an active Editorial Board member for various reputed international journals and an active reviewer for reputed IEEE, Springer and Elsevier international journals. He has also registered National and International Patents in the areas of Data Mining, Machine Learning and Metaheuristics.

Raviteja Kamarajugadda is working as an Assistant Professor in LBRCE. He received his M. Tech Degree in 2013 from Acharya Nagarjuna University. B. Tech from JNTU Kakinada in 2011. His research interests includes image processing, artificial intelligence, machine learning. 


\section{APPENDIX}

\section{Figure 1.}

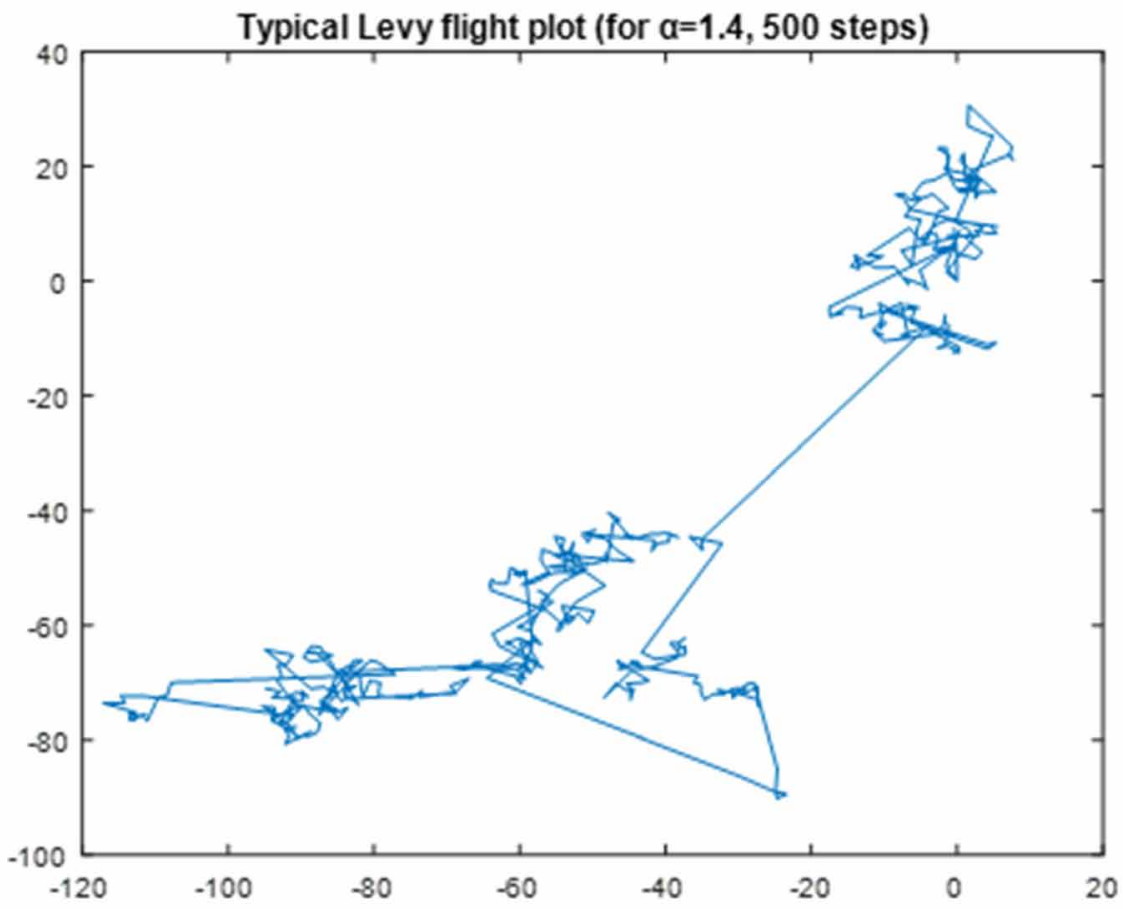


Figure 2.

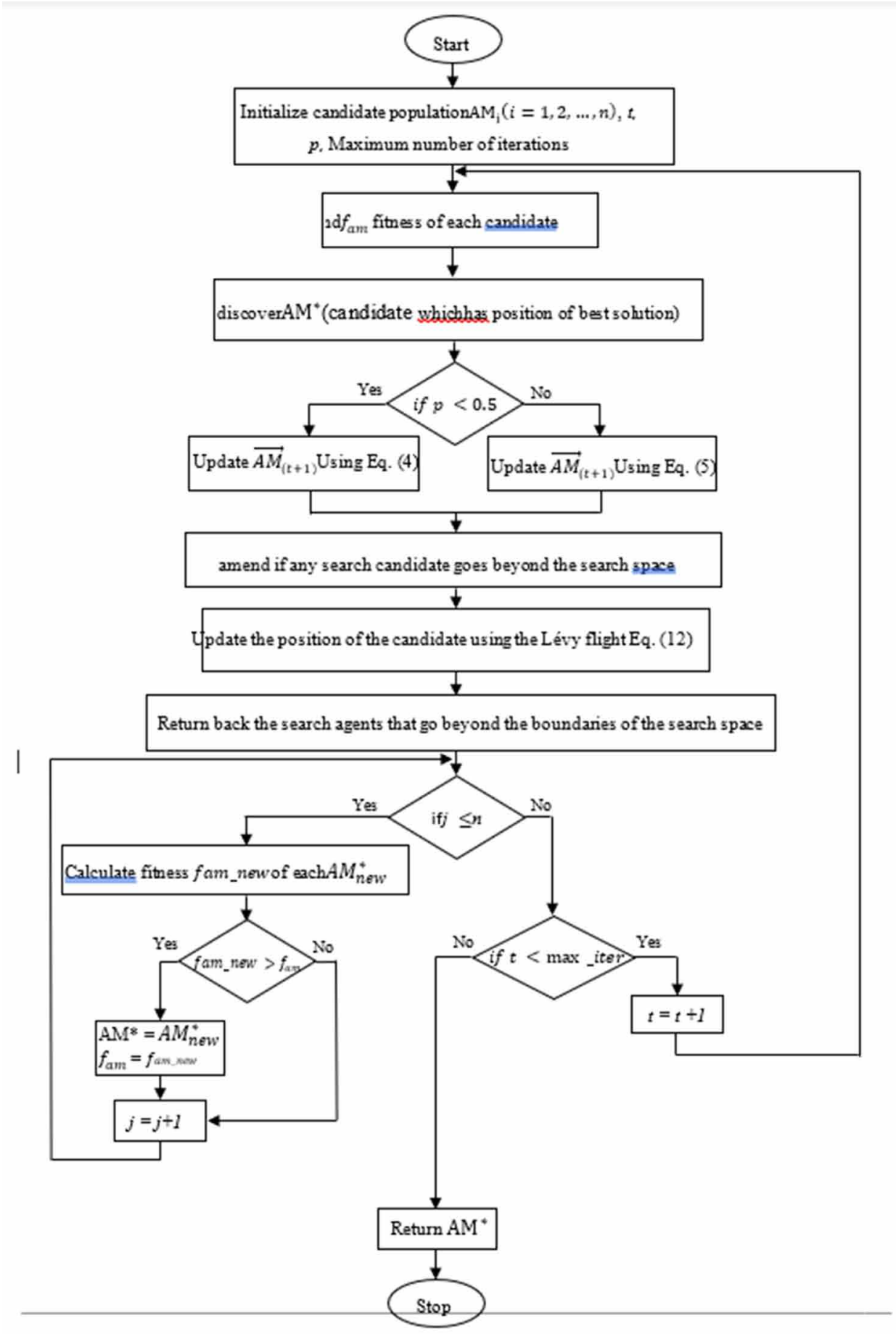


Figure 3a.
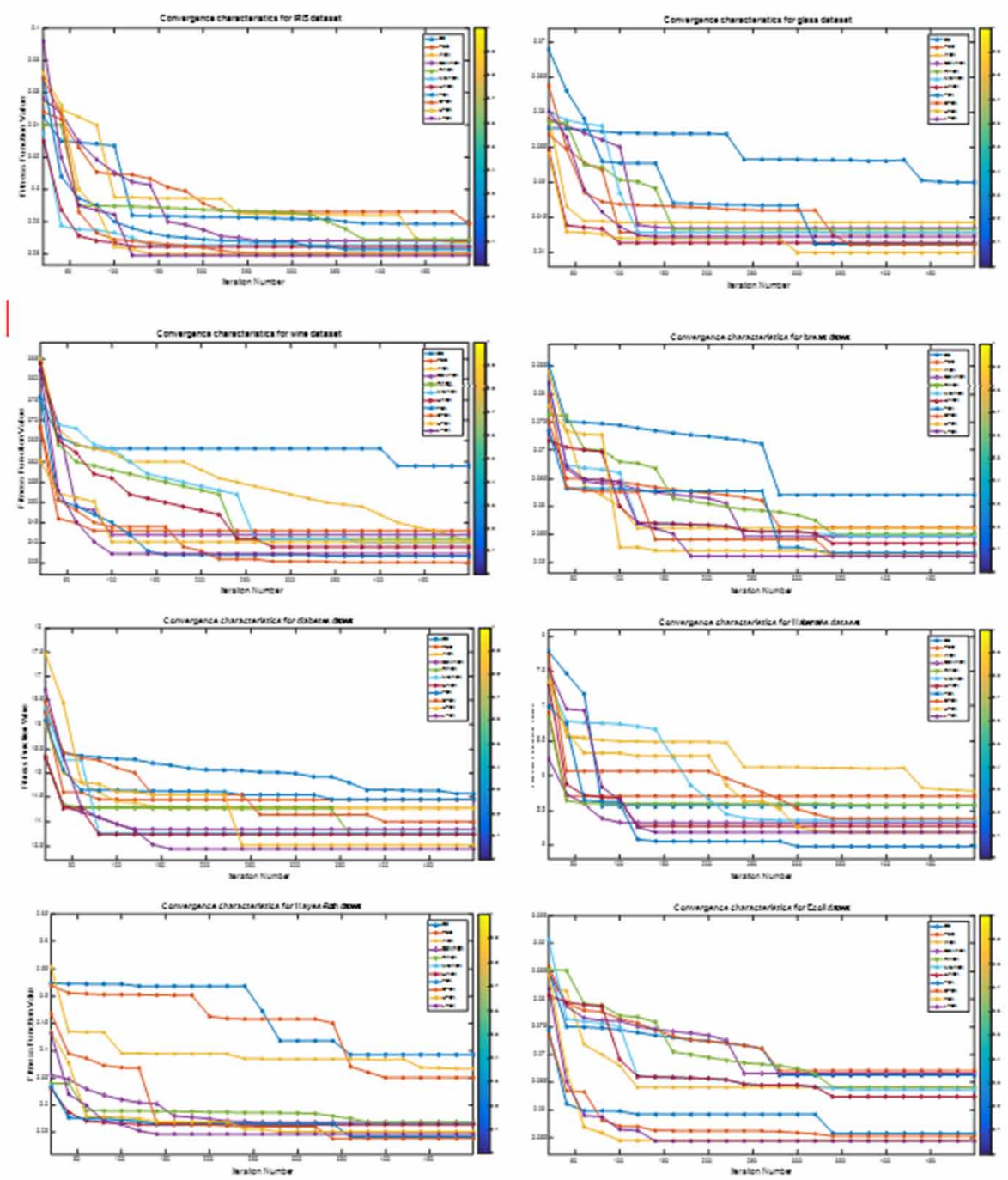

Figure 3b.
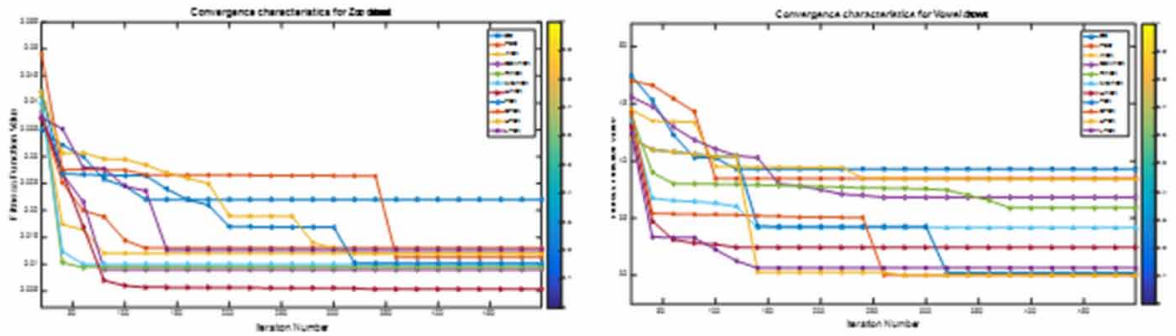